\title{
Preparation and Applications of Electrospun Optically Transparent Fibrous Membrane
}

\author{
Yanan Xiao, Hao Luo, Rongxing Tang and Jiazi Hou *
}

Citation: Xiao, Y.; Luo, H.; Tang, R.; Hou, J. Preparation and Applications of Electrospun Optically Transparent Fibrous Membrane. Polymers 2021, 13, 506. https://doi.org/10.3390/ polym13040506

Academic Editor: Gianluca Cicala Received: 19 January 2021

Accepted: 3 February 2021

Published: 8 February 2021

Publisher's Note: MDPI stays neutral with regard to jurisdictional claims in published maps and institutional affiliations.

Copyright: (C) 2021 by the authors Licensee MDPI, Basel, Switzerland. This article is an open access article distributed under the terms and conditions of the Creative Commons Attribution (CC BY) license (https:/ / creativecommons.org/licenses/by/ $4.0 /)$.
Key Laboratory of Automobile Materials, Ministry of Education, College of Materials Science and Engineering, Jilin University, Changchun 130025, China; ynxiao20@mails.jlu.edu.cn (Y.X.); haoluo@jlu.edu.cn (H.L.); tangrx20@mails.jlu.edu.cn (R.T.)

* Correspondence: houjiazi@jlu.edu.cn; Tel.: +86-133-2431-0438

\begin{abstract}
The optically transparent electrospun fibrous membrane has been widely used in many fields due to its simple operation, flexible design, controllable structure, high specific surface area, high porosity, and unique excellent optical properties. This paper comprehensively summarizes the preparation methods and applications of an electrospun optically transparent fibrous membrane in view of the selection of raw materials and structure modulation during preparation. We start by the factors that affect transmittance among different materials and explain the light transmission mechanism of the fibrous membrane. This paper also provides an overview of the methods to fabricate a transparent nanofibrous membrane based on the electrospinning technology including direct electrospinning, solution treatment after electrospinning, heat treatment after electrospinning, and surface modification after electrospinning. It further summarizes the differences in the processes and mechanisms between different transparent fibrous membranes prepared by different methods. Additionally, we study the utilization of transparent as-spun membranes as flexible functional materials, namely alcohol dipstick, air purification, self-cleaning materials, biomedicine, sensors, energy and optoelectronics, oil-water separation, food packaging, anti-icing coating, and anti-corrosion materials. It demonstrates the high transparency of the nanofibers' effects on the applications as well as upgrades the product performance.
\end{abstract}

Keywords: electrospinning; optically transparent; nanofibrous membrane

\section{Introduction}

Electrospinning, referred to electrostatic spinning, is one of the simple and effective methods to prepare continuous fibers with diameters ranging from nanometers to micrometers. Different from the traditional spinning method, electrospinning is a process in which polymer solution or melt is stretched by means of high-voltage electric field and finally solidified into fibers [1]. Electrospun fibrous membrane materials have been widely used in biomedicine, photoelectric materials, filtration, and adsorption due to their flexible design, controllable structure, high specific surface area, good adsorption, and permeability [2-4].

In particular, transparent as-spun membranes have attracted public attention due to their excellent optical properties. It is worth noting that in 1999, the first article on a transparent electrospun membrane was published, in which Bergshoef and Vancso impregnated the as-spun PA-4,6 nanofibers with resin, drying, and curing for $60 \mathrm{~h}$, and they obtained the transparent fiber membrane [5]. In the ensuing 20-year period, the number of published articles about transparent electrospun membranes has been increased from 1 to 55 a year, which implies that the preparation and application of transparent electrospun fibrous membranes have attracted the attention of researchers. Among them, research studies on transparent fiber materials are mainly concentrated on materials science, accounting for $74.164 \%$ of the total literature (as shown in Figure 1). 
a

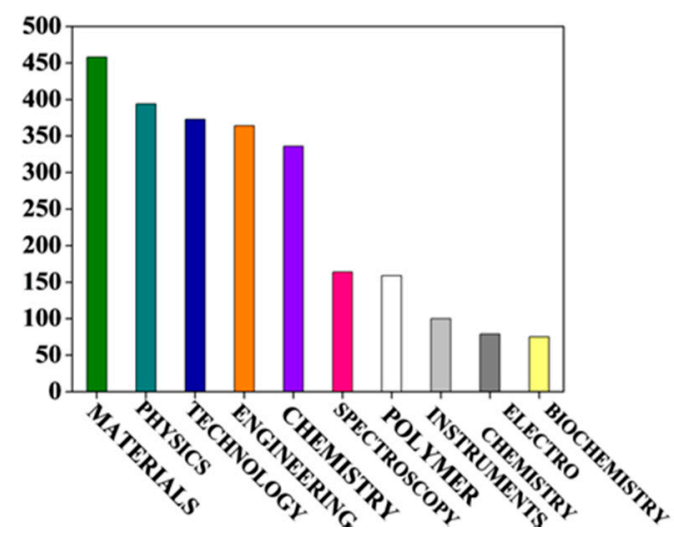

b

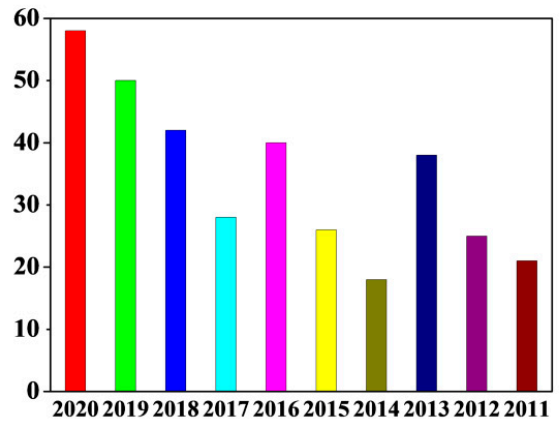

Figure 1. (a) Quantitative statistics of related articles on transparent as-spun nanofibers literature in various academic fields. (b) Statistics on the number of articles on electrospun transparent fiber membranes published each year in the last 20 years.

During the last decade, the transparency of the as-spun membrane was based on transparent raw materials and structure modulation. As a transparent material, polystyrene (PS) nanofiber prepared by electrospinning was a transparent matrix to encapsulate $\mathrm{CsPbBr}_{3}$ nanocrystals (NCs). These made a type I core-shell structure. [6]. In order to modulate the structure easily, researchers were more likely to choose easy processing and soluble materials, such as polyethylene terephthalate (PET). Du [7] used the spectrophotometer to test the light transmittance of the material and found that the microstructure such as the areal density of PET nanofibers was significantly changed by adjusting the concentration of the PET spinning solution. As the areal density increased, the transmittance decreased. The main reason is that with the areal density increasing, the refractive indices of air and fibers at the interface increase. When electrospinning $\mathrm{TiO}_{2}, \mathrm{Li}[8]$ observed that with the electrospinning time extension, the thickness of the membrane increased and the transmittance gradually decreased. Hence, many factors determine the transmittance of an as-spun membrane, such as the refractive indices, the thickness of the membrane, and the transparency of raw materials. Moreover, there are common methods to test the light transmittance of an as-spun membrane, namely spectrophotometer [9], transmittance meter [10], and integrating sphere photometer [11]. The above methods are noninvasive testing technologies, and the membrane structure is not destroyed. All in all, appropriate material selection, structure modulation, and testing methods contribute to the development of preparation and characterization of transparent as-spun membranes.

Apart from this, the increase demand on various fields has fueled the development of the transparent fibrous materials. On the one hand, the improvement of light transmittance broadens applications of fibrous membrane, such as transparent wound dressing, which not only promotes wound healing but also provides a rapid visual window for wound detecting, so as to avoid the secondary injury of patients caused by its frequent openingclosing [12]. On the other hand, the application of transparent fibrous membranes improves the performance of products. As far as optical fibrous solar cells are concerned, excellent optical performance can effectively improve the energy utilization and photoelectric conversion efficiency [13]. In addition, according to the change of transparency, it directly observes membrane durability and confirms the product life for the timely replacement of the material, such as filtration and adsorption materials [14,15]. Therefore, in the light of the above advantages, the development of electrospun fibrous membrane with excellent light transmission performance will broaden the application scope of micro-/nano- membrane materials and promote the technological upgrading (as shown in Figure 2). 


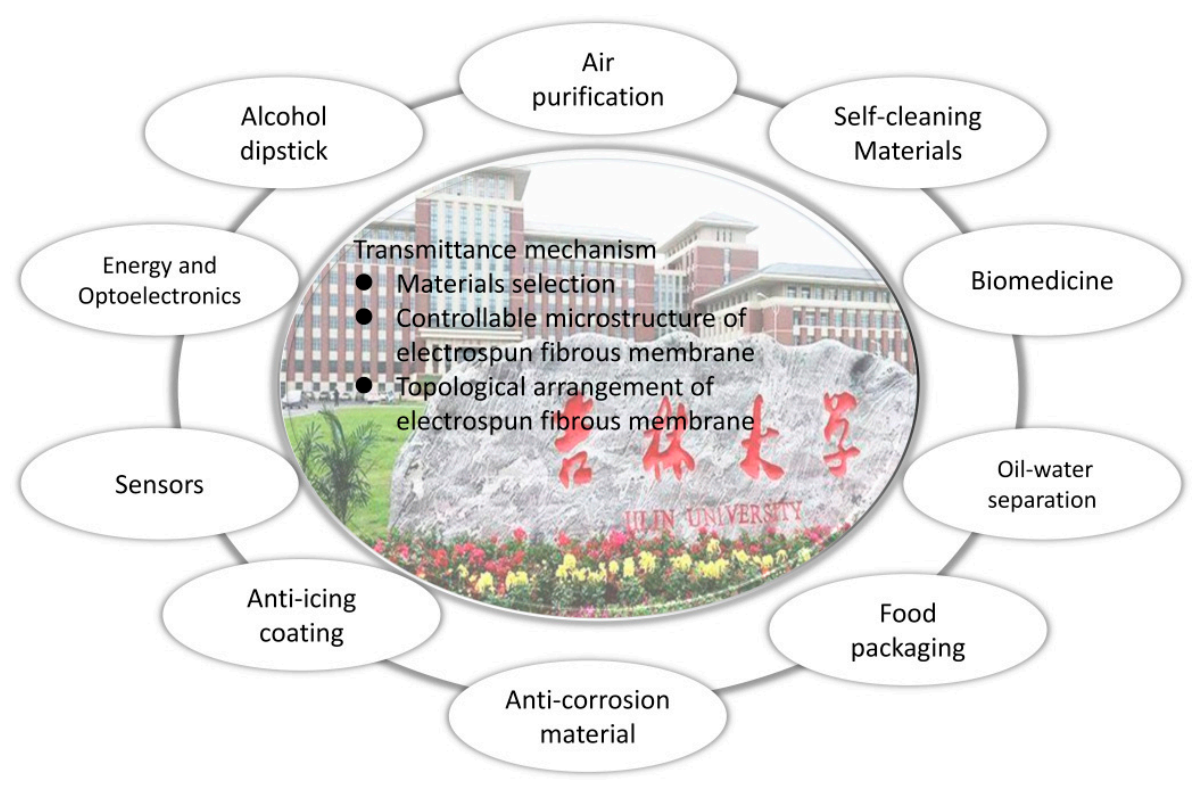

Figure 2. The applications of transparent as-spun membranes.

In recent years, some researchers studied electrospun nanofibrous membranes with high transmittance used for various applications involved in air purification, biomedicine, sensors, etc. However, there is no review to summarize light transmission mechanism, raw materials, fabrication techniques, and applications. This article could benefit beginners who are eager to become familiar with electrospun optically transparent fibrous membranes, having preliminary understanding and moving to a deeper mastery of that.

\section{Optically Transparent Materials}

Transmittance refers to the percentage of the transmitted light flux to the incident luminous flux on the surface of transparent materials [16]. It is an important performance to characterize the degree of transparency of materials. The higher the transmittance, the more transparent the materials. For various materials, such as metals, ceramics, and polymers, according to the difference of bonds, microstructure, and properties, the factors that affect transmittance are different, varying from material to material.

\subsection{Ceramic Materials}

Most ceramic materials are opaque in the visible light range. Only by adjusting the crystal structure by physical or chemical means can the materials show high transmittance. According to Rayleigh scattering theory, the size of nanocrystals must be far smaller than the wavelength of visible light, and the refractive index of crystal phase must be close to that of the matrix [17-19] in order to prepare transparent crystal materials. In other words, the optical transparency of ceramics is closely related to the size and concentration of nanocrystals.

The transparency of ceramic materials largely depends on the optical anisotropy of residual pores and defects, second phase inclusions, rough surfaces, and crystals [20-23]. As a result, by controlling the content of additives, the transmittance of ceramic materials can also be very high. Miao et al. [24] explored the relationship between the addition of calcium fluoride $\left(\mathrm{CaF}_{2}\right)$ and light transmittance by changing the amount of $\mathrm{CaF}_{2}$ in transparent glass-ceramic (TGCs) materials. When the $\mathrm{CaF}_{2}$ content was $15.4 \mathrm{wt} \%, 20.4 \mathrm{wt} \%$, and $35.4 \mathrm{wt} \%$, the aluminum silicate polycrystalline crystals were formed in the glass ceramic sample, and the TGCs were opaque. When the $\mathrm{CaF}_{2}$ content increased to $27.4 \mathrm{wt} \%$, $\mathrm{CaF}_{2}$ was used as a nucleating agent to make the glass matrix crystallize early. Then, nanocrystals were formed through heat treatment with the size much smaller than the wavelength of visible light. Meanwhile, the refractive index of the crystal phase was 
close to that of the glass matrix, which was in accordance with Rayleigh scattering theory. Therefore, the TGCs were highly transparent.

The reason for the low light transmittance of dielectric ceramics is the various lightscattering locations, such as residual pores on rough surfaces and second phase at grain boundaries [25-27]. Zhang et al. [28] improved the compactness of the $\left(\mathrm{K}_{0.5} \mathrm{Na}_{0.5}\right) \mathrm{NbO}_{3}$ $(\mathrm{KNN})$ matrix and reduced the porosity of the crystal by reducing the grain size and removing the impurities in the crystal. The transmittance of the KNN-based ceramics had been significantly improved. Belyaev et al. [29] prepared $\mathrm{Co}: \mathrm{ZnAl}_{2} \mathrm{O}_{4}$ transparent ceramics by the hot-pressing method and explored the influence of the content of cobalt $(\mathrm{Co})$ and sintering additive $\left(\mathrm{ZnF}_{2}\right)$ on the ceramics transparency. It was found that when the content of $\mathrm{Co}$ and $\mathrm{ZnF}_{2}$ was in the range of 3-10 $\mathrm{wt} \%$, the average grain size was in the range of 50-70 mm, which made ceramics compact on the micro-scale and highly transparent on the macro-scale. Chen et al. [30] synthesized nanopowders by the co-precipitation method and then fabricated Ce: $\mathrm{Gd}_{2} \mathrm{YGa}_{3} \mathrm{Al}_{2} \mathrm{O}_{12}$ transparent ceramics by the two-step-sintering that is pre-sintering and hot-isostatic-pressing. The key to achieving transparency is high density, fine grains, and little residual intergranular pores, which can be tailored by controlling the sintering process.

In conclusion, it was indispensable to maximize the size of nanocrystallines smaller than wavelengths of visible light, lower the porosity, and increase the density.

\subsection{Metal Materials}

With a special structure, a fraction of metal materials and organometallic compound is transparent, such as nanoparticles [31], nanonets [32], and nanowires [33,34]. Most incident light can pass through the metal grids to achieve high transmittance, while only a little incident light is refracted and lost. Kubwimana [35] prepared a metal conductive grid on the top of the Lexan substrate with a transmittance of $84.5 \%$. Owing to the fact that transparency is the percentage ratio of no metal areas to metal areas, the array antenna reached high transmittance by adjusting the pitch of mesh material. Therefore, the structure of metal materials has an important impact on the transmittance. Lee et al. [36] prepared Ag nanowires (AgNWs) transparent films with excellent photoelectric properties and introduced the value of merit ( $F o M)$ to define the trade-off between conductivity and optical transparency.

$$
\text { FoM }=\frac{188.5}{\operatorname{Rs}\left(\mathrm{T}^{-\frac{1}{2}}-1\right)}
$$

where Rs is the sheet resistance and $\mathrm{T}($ at $\lambda=550 \mathrm{~nm}$ ) is transmittance. The formula quantitatively displayed that the larger the FoM value, the lower the sheet resistance and the higher the transmittance.

Oxygen doping is also an effective method to reduce metal optical loss and improve transmittance. Zirconium $(\mathrm{Zr})$ is an opaque metal in the visible light range. Under the two-step oxidation process combining air heat treatment and low oxygen partial pressure, $\mathrm{Zr}$ metal foil can be prepared into doped and transparent monoclinic $\mathrm{ZrO}_{2}$, and the transmittance reached $60 \%$. The monoclinic transparent $\mathrm{ZrO}_{2}$ was composed of equiaxed grains of tens of nanometers and columnar crystals of several microns in length [37]. Additionally, Jo et al. [38] used oxygen as dopant in the silver metal layer. The average transmittance of the optimized silver metal layer was $93.5 \%$ in the range of $500-800 \mathrm{~nm}$, and the optical loss was reduced to $1.01 \%$.

Improving the dispersion of metal on the carrier is also an effective way to improve the transmittance of organometallic compound. Wu et al. [39] used the impregnation deposition method to load $\mathrm{Pt}$ catalytic centers on $\mathrm{Mo}_{2} \mathrm{C}$. There was a strong electronic effect between $\mathrm{Mo}_{2} \mathrm{C}$ and Pt clusters, and Pt clusters had small size, good dispersion, and low loading on the carrier, which prevented $\mathrm{Pt}$ aggregation from absorbing and scattering light. 


\subsection{Polymer Materials}

Different from metal and ceramic materials, the transparency of polymer materials mainly depends on its crystallinity [40]. The polymers with high crystallinity will increase light reflection, resulting in high light loss and low light transmittance. Polycarbonate (PC), an amorphous polymer with low crystallinity, has high light transmittance and could be used as a transparent matrix. For instance, Park et al. [41] adopted a biomass-derived isosorbide instead of bisphenol A to prepare a PC nanocomposite with higher transmittance than pure PC. Moreover, PET [42], PMMA [43], and PS [44] are also introduced as a transparent matrix for their low crystallinity. Kim et al. [45] mimicked the surface structure of the Progomphus obscurus (sanddragon) wing, physically killing the attached bacteria, and they prepared a transparent, colorless, and self-disinfecting polyethylene terephthalate (PET) film by plasma treatment.

For other opaque polymers, chemical treatment and composite modification are needed to obtain transparent products. For example, the optical transparence of natural wood could be significantly improved by the chemical removal of chromogenic groups and lignin, and the penetration of polymers with a suitable refractive index, such as polyvinyl alcohol (PVA) [46,47], epoxy resin [48] and polyimide (PI) [49]. Using epoxy resin as a permeation polymer, Mi et al. [50] prepared transparent wood with light transmittance up to $80 \%$, which has a good anti-glare performance and light-guiding properties (as shown in Figure 3). By the means of chemical treatment, the light transmittance of PI could be very high in the visible light range. Polyimide (PI) usually appears dark brown because of the charge transfer complex formed between the highly conjugated substituents imino group and the rigid benzene ring, which will introduce a monomer with a strong electron withdrawing group in the main chain of PI, preventing the electron movement on the main chain of PI [51,52]. Therefore, optically transparent PI (CPI) can be synthesized by changing the monomer structure. Kim and Chang [53] blended poly (amic acid) (PAA) and PVA with PI, and then, they heat-treated them to obtain a blend film of CPI and PVA. After removing PVA, a porous CPI film with high transmittance was obtained.

\section{a Aesthetic wood ceiling}

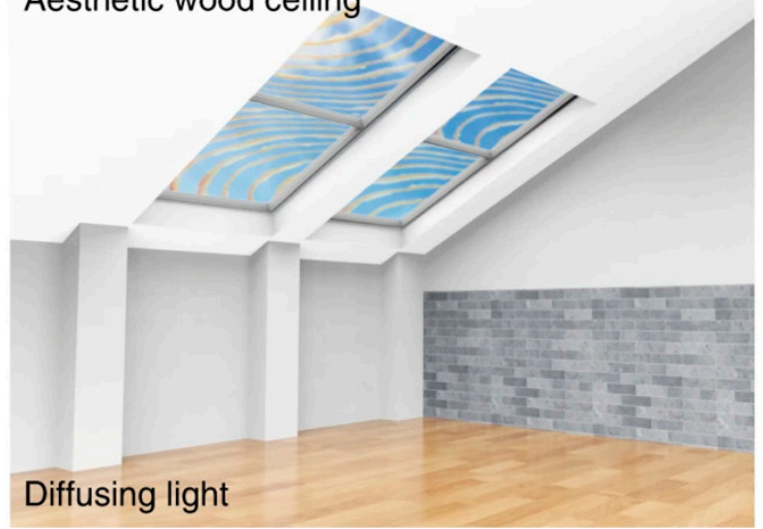

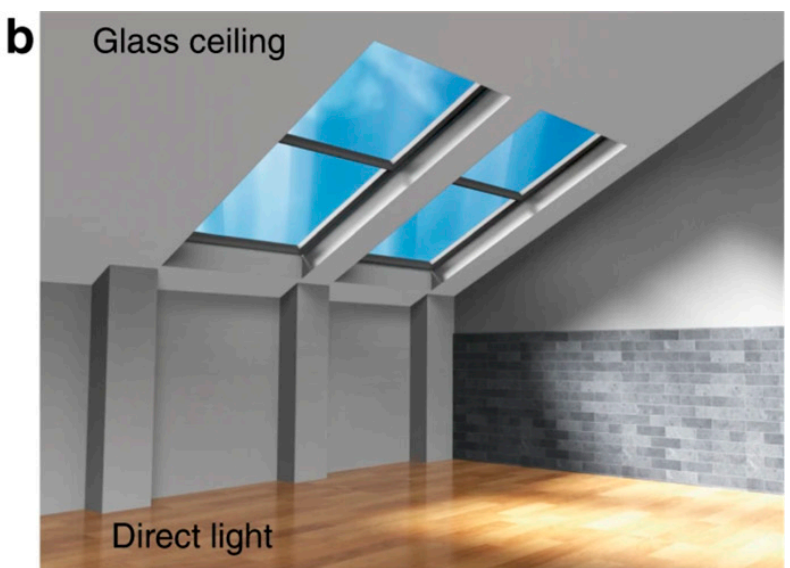

Figure 3. The schematic scene shows the light distribution and aesthetic appeal inside a building via applying (a) the aesthetic wood ceiling comparing with (b) the glass ceiling (Adapted from [50]).

Inorganic nanofillers with a high refractive index also effectively improve the transmittance of polymers. Tao et al. [54] filled the high refractive index $\mathrm{TiO}_{2}$ filler into the poly (glycidyl methacrylate) (PGMA) polymer chain through covalent action, which realized the space-shielding effect, reduced light scattering, and prevented the aggregation of inorganic nanoparticles. The light transmittance of the prepared polymer material was as high as $90 \%$. 


\section{Light Transmission Mechanism of Electrospinning Fibers}

Due to the flexible selection of an electrospun matrix, it is easily to obtain various fibrous membranes made of ceramics, metals, and polymers. However, the enhanced transparency of an electrospun fibrous membrane is still a challenge because of its unique interconnected networks. The main reason is that when the incident light hits an interface, the light will spread in different forms, including transmission, reflection, refraction, scattering, or absorption. Among them, the reflection of light is the main factor causing light loss, and with the increase of the interface area, the light loss continues to increase [55].

Electrospinning membranes have numerous interconnected pores, which inclines to form dozens of air-fiber interfaces. Therefore, a large amount of reflection/refraction loss occurred at these interfaces, which eventually made the membrane opaque. So, the effective method to reduce the light loss is adjusting the pores of electrospun fibrous membrane and building an interface with little light loss. The reflection of incident light at the interface is related to the refractive index of the two heterogeneous materials forming the interface [56], which is expressed by the following formula:

$$
\Gamma=\left[\frac{n_{1}-n_{2}}{n_{1}+n_{2}}\right]^{2}
$$

where $\Gamma$ is the reflection coefficient, and $n_{1}$ and $n_{2}$ are the refractive indices of air and fibers at the interface, respectively. Since the refractive index difference between the air and fibers leads to the increase of the reflection, reducing the refractive index difference of the heterogeneous materials at the interface improves the optical transparency of the fibrous film.

There are two kinds of transmittances: specular transmittance and diffusive transmittance. For specular transmittance, the photo-detector only measures the light that transmits along the same axis as the incident. For diffusive transmittance, the transmitted light is collected at all angles by an integrating sphere [57].

When a photon encounters an object, it can interact with it via refection, adsorption, or refraction. However, light scattering, especially forward scattering (namely diffusive transmittance), will cause an optical haze effect that possesses excellent optical management capability including the anti-glare effect and light guiding, which are of great significance for transparent ceiling applications but are detrimental for indoor displays. The light management of transparent substrates is extremely important for optoelectronic devices. For example, an increased absorption path of light in a solar cell will enhance the device's conversion efficiency; thus, a considerable light scattering is preferred. An anti-glare coating is needed for display-driven devices to function in bright environments, such as for touch screens in global positioning systems (GPS). For such applications, an anti-glare coating with large light scattering is required. Therefore, it is very important to be able to tailor the light scattering of the transparent substrates for different applications.

Other factors such as the nanofibers' diameter have also occupied a prominent position because it would have an effect on the propagation process of light. Light is an electromagnetic wave in theory; thus, visible light can pass fibers of $<400 \mathrm{~nm}$ in diameter without the occurrence of reflection and/or refraction at the fiber/matrix interface. Light undergoes reflection and/or refraction upon reaching nanofibers whose diameters are larger than $400 \mathrm{~nm}$. The total diffusive transmittance does not vary much as the fiber diameter is smaller than $400 \mathrm{~nm}$. However, specular transmittance and the haze values change dramatically in the visible wavelength range. Li et al. [58] utilize a self-blending co-electrospinning (SBCE) to prepare aligned fiber-hybrid mats consisted of "uniaxially" oriented and well-mingled PA-6 nanofibers as the reinforcement and PMMA microfibers as the matrix. The PA-6/PMMA fiber-hybrids are subsequently fabricated into optically transparent nanocomposite sheets by hot press molding. Thereafter, the nanofiber directionality effects on the optical transmittance and mechanical properties of the thus-produced PA-6/PMMA nanocomposite in two orthogonal directions are sequentially evaluated. 
They find that transmittance of the 1\% PA-6/PMMA nanocomposite can be remarkably enhanced with PA-6 nanofibers prepared at increasing rotating speeds. This is because higher rotating speeds facilitate the generation of nanofibers with a decreased diameter (as shown in Figure 4).

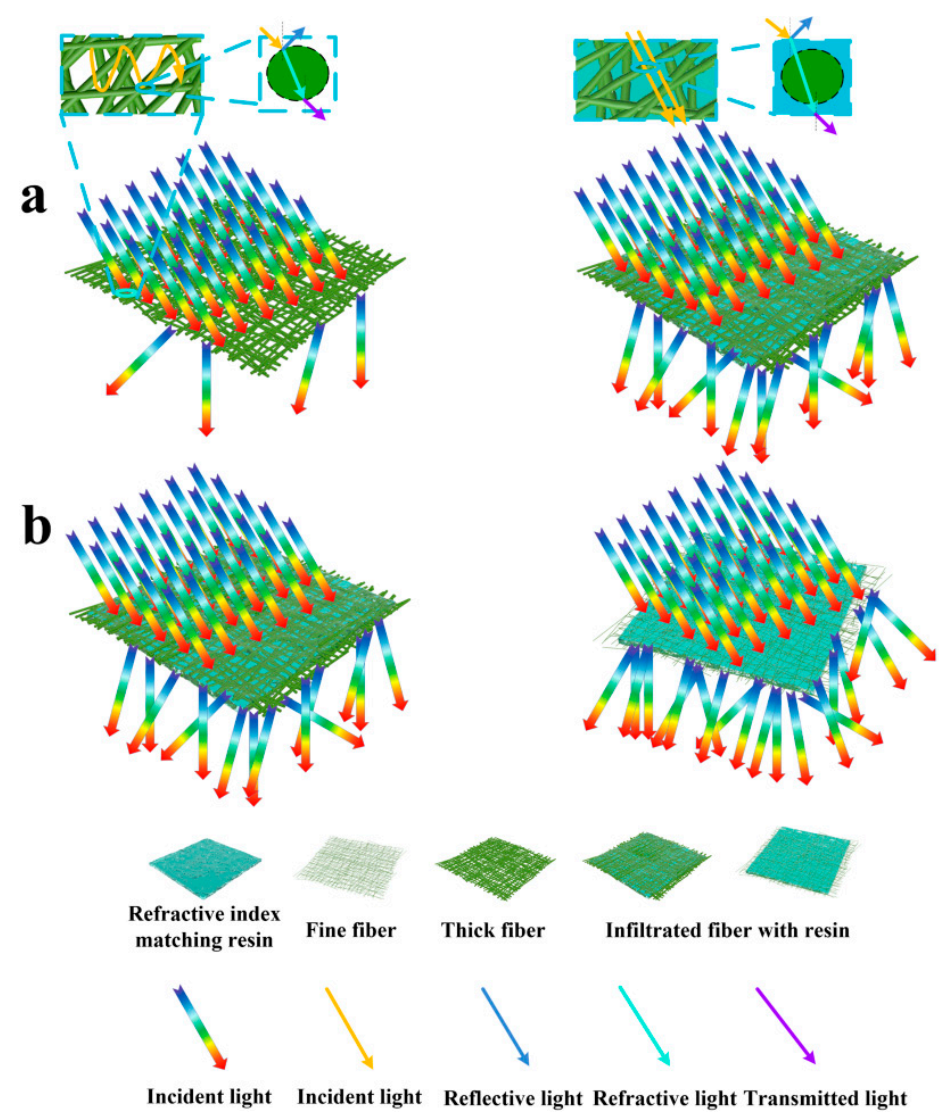

Figure 4. Schematic diagram of the influence of refractive index, (a) electrospun fibers diameter and (b) refractive index on light propagation (the number of arrows represents light intensity).

Therefore, according to the light transmission mechanism of electrospinning fibers, some research studies on material selection and structure modulation are conducted to obtain an as-spun fibrous membrane with high transparency.

\subsection{Materials Selection}

Many common materials including polycarbonate (PC), polyethylene terephthalate (PET), polymethyl methacrylate (PMMA), polystyrene (PS), and other materials such as nylon, epoxy resin, and thermoplastic polyurethane are optically transparent. Using transparent raw materials could obtain electrospun fibrous membrane with high light transmittance directly. For example, the raw material of thermoplastic polyurethane (TPU) fibrous membrane is transparent with a light transmittance of $90 \%$, which still maintains a high light transmittance after electrospinning [10]. PS is one of the five transparent plastics with a light transmittance of more than $90 \%$. The modified PS fibrous film via electrospinning also showed excellent optical transparency [59].

However, the transparency of most electrospun fibrous membranes is not high. To improve the light transmittance of electrospun fibers, it can be achieved by compounding with transparent polymer materials. The common methods include impregnation, hot pressing, surface modification, etc. For instance, a polyacrylonitrile (PAN) electrospun fibrous membrane is white in the visible light range, while it shows excellent optical transparency after being immersed in PMMA solution with high transmittance. The transmittance of the composite membrane in the visible light range increased to $90 \%$ [55] 
(as shown in Table 1). The transparency and mechanical properties of PA-6/PMMA transparent composite fibrous membrane with a core-shell structure are much higher than that of the PA- 6 nanofibrous membrane because of the more uniform distribution and less aggregation of PA-6 nanofibers in the core-shell structured fibers membrane [60].

\subsection{Controllable Microstructure of Electrospun Fibrous Membrane}

Packing density or excellent interfacial adherence among fibers could not be ignored for light transmittance, because the air within the nanofibers internal structure will increase light scattering and reduce the transmittance. Cai et al. [61] deacetylated bamboo source cellulose to prepare cellulose acetate (CA) material. By adjusting the receiving device, the nanofibers with uniaxial arrangement were fabricated. Then, the fibrous membrane was immersed in PVA solution. Since the refractive index difference between CA fibers and PVA resin is far less than that between CA and air, a composite membrane with a light transmittance of $75 \%$ was obtained (as shown in Figure 5).

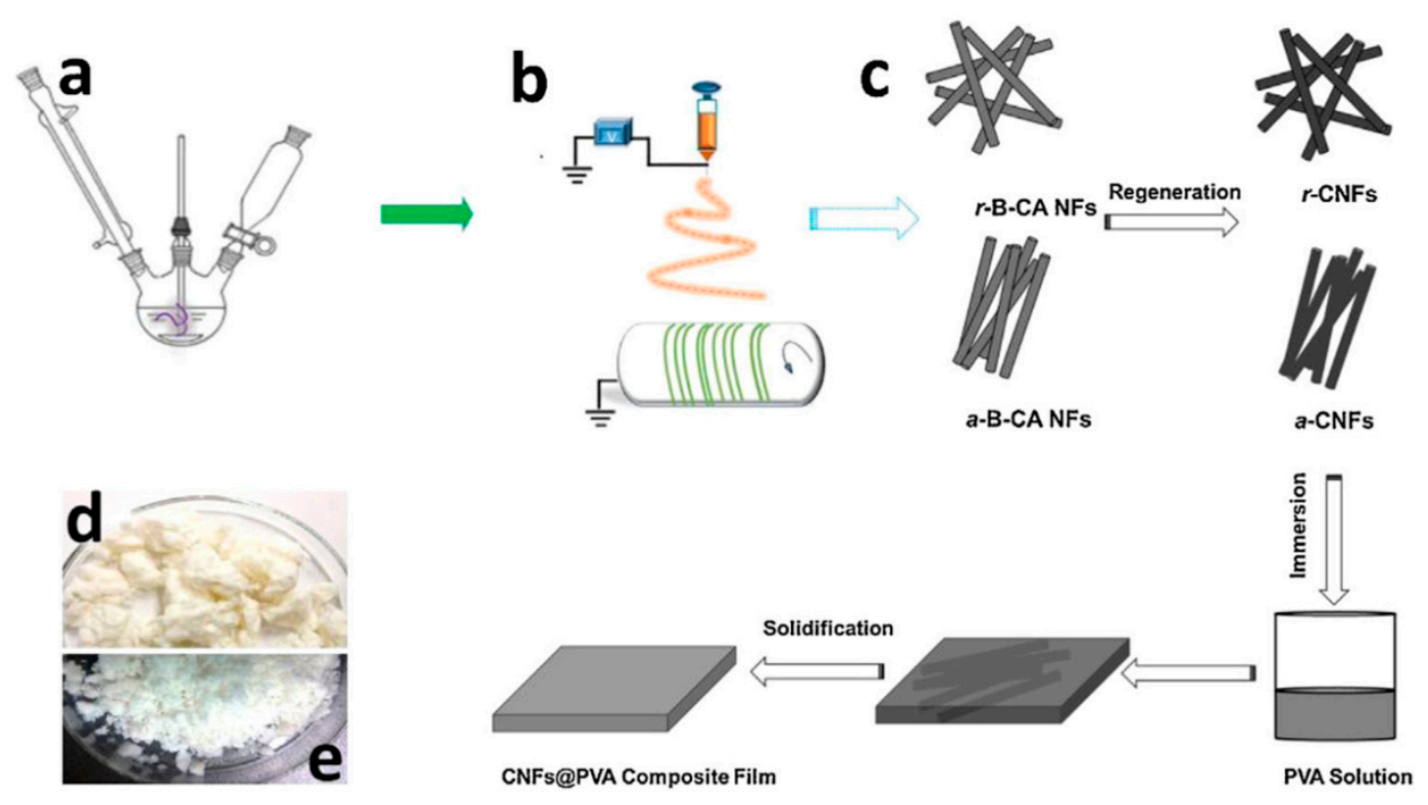

Figure 5. Schematic illustration of (a) acetylation reaction, (b) electrospinning, (c) CNFs@PVA composite films preparation process, and (d,e) photographs of bamboo cellulose (BC) and B-CA (Adapted from [61]). CA: cellulose acetate, PVA: polyvinyl alcohol (Adapted from [61]).

\subsection{Topological Arrangement of Electrospun Fibrous Membrane}

For the material without transparency, the design of its topological arrangement can reduce the membrane thickness and effectively improve its transmittance. Polycaprolactone (PCL) is a kind of degradable plastic, and it can be electrospun into white fibers with low transmittance [62]. Pan et al. [63], inspired by the woven structure of the window screen, improved the preparation method of a PCL electrospun fibrous membrane, and electrospun it to deposit fibers with anisotropic thickness gradients. Most of the fibers were densely packed on the wires in a small area, while very few fibers were sparsely suspended in the voids over a large area. (Most of the fibers were densely distributed on the wire mesh, and a few of them were sparsely suspended in the space among the wire meshes.) Light was easy to pass through the suspended fibers, which greatly improved the overall light transmittance of the macro structure of the fibrous membrane, compared with the isotropic fibrous membrane, showing optical transparency. 


\section{Preparation Methods of Transparent Electrospun Fibrous Membrane}

Several research studies are developed to achieve transparent electrospun fibrous membranes. Direct electrospinning and post treatment after electrospinning as the main methods are employed to increase the optical transparency of the fibrous membrane.

\subsection{Direct Electrospinning}

Direct electrospinning heavily depends on the selection of high light transmittance materials, while the fiber diameter and film thickness also have a significant impact on the light transmittance [64]. Li et al. [8] prepared a kind of self-cleaning transparent titanium dioxide $\left(\mathrm{TiO}_{2}\right)$ nanofilm on the glass substrate by direct electrospinning. The diameter of the fibers was $50 \mathrm{~nm}$, and the thickness of the film was $5 \mu \mathrm{m}$. The specific method was to add a series of different contents of diethanolamine (DEA) into the polymer polyvinylpyrrolidone (PVP) solution of $\mathrm{TiO}_{2}$, place the transparent glass substrate in front of the aluminum foil to collect, and finally remove organic components to get $\mathrm{TiO}_{2}$ nanofilm by high-temperature sintering. With the content of DEA increasing, the morphology of the films deposited on the slide changed from opaque to transparent. Additionally, adjusting the electrospinning time to control the film thickness is also an effective method to improve the transmittance. Chen et al. [10] prepared an elastic TPU electrospun fibrous membrane with a diameter distribution of $0.82 \pm 0.22 \mu \mathrm{m}$; by collecting for $10 \mathrm{~min}$, the fibrous membrane was transparent in the visible light range, and the light transmittance reached more than $60 \%$.

In addition, polymethyl methacrylate (PMMA) and its modified materials are often used as the matrix of direct electrospinning to prepare high-transmittance fibrous films. PMMA is transparent because of its large side group, irregular crystal structure, and complete light transmission. For the electrospun PMMA, its fiber diameter is smaller than the wavelength of visible light, and the transmission light loss is less, so it has a slight influence on the light transmittance [65]. Examples are the AgNWs [66], n-butyl acrylate/methyl methacrylate copolymer (BA-co-MMA) electrospun fibrous membrane [67], polymethylmethacrylate/tungsten disulfide (PMMA/ $\mathrm{WS}_{2}$ ) composite nanofibrous membrane [68], and tungsten oxide/organic framework/polymethylmethacrylate $\left(\mathrm{WO}_{2} / \mathrm{PEDOT} / \mathrm{PMMA}\right)$ conductive nanohybrid fibers [69].

Furthermore, Gan and Zhang [70] fabricated thermoplastic polyurethane (TPU) nanofiber/ net membranes with high transparency by electrospinning. Adopted DMF and acetone as solvent, TPU elastomer, and various $\mathrm{LiCl}$ salt amounts were put into the mix to prepare the precursor. Ruan et al. [71] obtained the transparent $\mathrm{PAN}$ : $\mathrm{TiO}_{2}$ and polyacrylonitrileco-polyacrylate: $\mathrm{TiO}_{2}\left(\mathrm{PAN}-\mathrm{co}-\mathrm{PMA}: \mathrm{TiO}_{2}\right.$ ) nanofiber membranes composite nanofiber membranes by direct electrospinning as well. $\mathrm{TiO}_{2}$, PAN, PAN-co-PMA, and PVP were added to the DMF solution to prepare the mixed procedure. The obtained membranes exhibited high transparency and excellent air permeability. Meanwhile, Salehi [72] adopted poly- $\varepsilon$-caprolactone (PCL)-silkfibroin (SF) as raw materials to fabricate a hybrid scaffold through electrospinning. In comparison with non-aligned scaffolds, the aligned PCL-SF scaffolds displayed higher transparency, hydrophilicity, and water uptake.

Other transparent electrospun systems, such as nano diamond/nylon-11/polyacrylonitrile (ND/PA-11/PAN) [73], keratin/polyvinyl alcohol/carbon quantum-dot (keratin/PVA/cdot) [74], can also be directly electrospun into transparent fibrous membranes. The transmittance of all above materials is up to $82 \%$.

\subsection{Solution Treatment after Electrospinning \\ 4.2.1. Solution Casting}

Solution casting is the process of dispersing the electrospun fibers in the matrix solution with high transmittance by stirring or ultrasonic techniques. With the casting solution evaporating and drying, the transparent membrane is obtained. This method is usually used for the preparation of electrospun reinforcement materials. Jiang et al. [64] cut nylon-6 (PA-6) nanofibers by electrospinning to obtain discontinuous short fibers with an 
average diameter of $163 \pm 4.73 \mathrm{~nm}$ and length ranging from tens of microns to hundreds of microns and dispersed them in TPU and PMMA solutions, respectively. After casting and drying, PA-6/TPU and PA-6/PMMA nanofibers film were obtained simultaneously. The test results showed that PA- 6 short fibers had no significant effect on the transparency of TPU and PMMA films compared with the electrospun continuous fibers, and the light transmittance of the composite film was still over $86 \%$. Arrieta et al. [75] added D. antarctica, an extract from Antarctic alga, into PVA solution, obtaining D. antarctica/PVA composite fibers. Subsequently, it was dispersed in polylactic acid and formed a flexible and optically transparent fibrous membrane through casting (as shown in Figure 6).

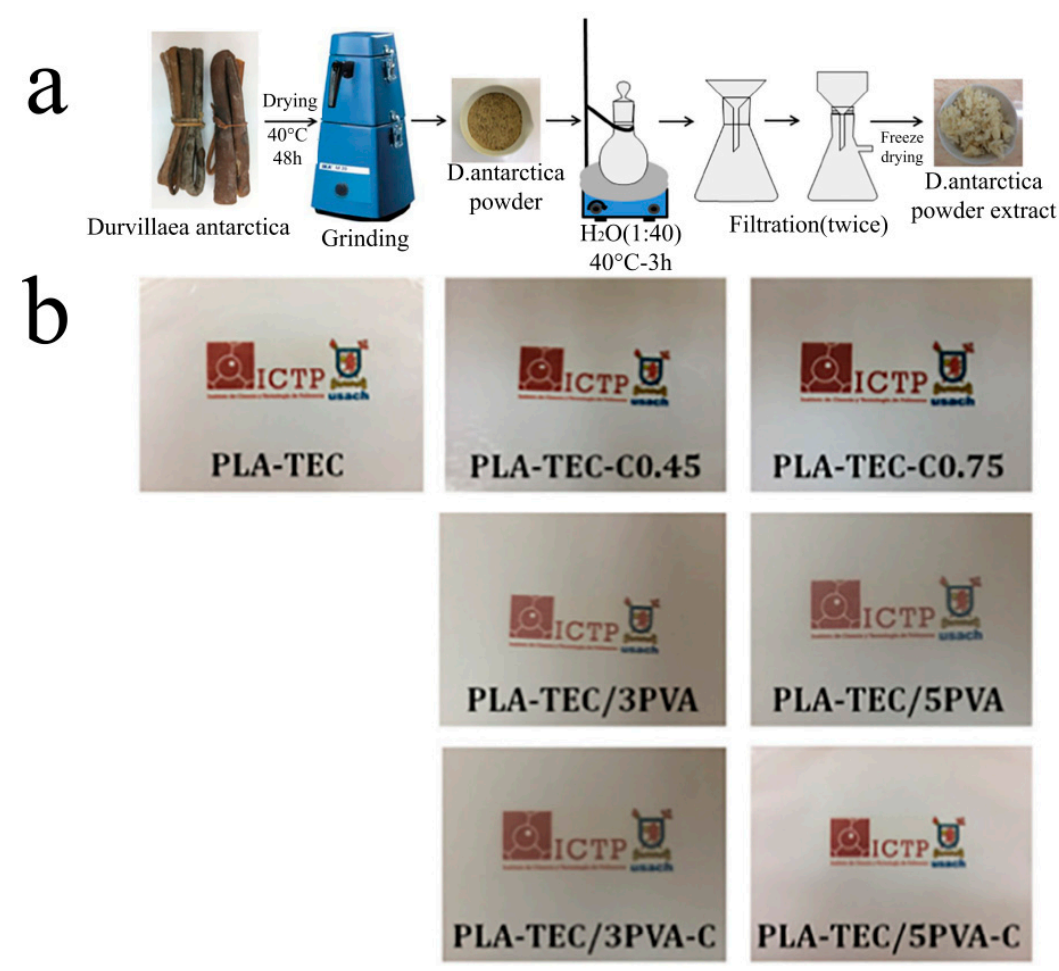

Figure 6. (a) Schematic representation of extraction procedure of $D$. Antarctica algae from natural algae to powder extract and (b) visual appearance of the obtained bionanocomposite films. (adapted from [75]).

\subsubsection{Dipping}

The non-transparent electrospun fibrous membrane can optimize its optically transparence by solution dipping. The method is to soak the as-spun fibrous membrane in a transparent solution and then dry the membrane after the fibrous membrane is fully soaked in the solution. The transparent solution fills the pores among the fibers, which greatly improves the light transmittance of the composite membrane.

The PVA solution has good transparence after drying, so it is often used as an impregnation solution of electrospun membrane. Najarzadekan and Sereshti [76] immersed the opaque polycaprolactam/1, 10-phenanthroline (PA-6/1, 10-phen) hybrid electrospun fibers into PVA aqueous solution, evaporated the solvent, and obtained a highly transparent fibrous membrane. Additionally, Stachewicz et al. [77] also used PVA as the impregnation solution and electrospun nylon-6 (PA-6) fibers as the reinforcement fibers to prepare optical transparent film by dipping. Moreover, the effect of PVA concentration in the impregnation solution on the light transmittance of the fibrous membrane was also discussed. The increase of PVA concentration led to more PVA entering into the porous nanofibers, the porosity of the film decreased, and the optical transparency increased. When the concentration of PVA reached $20 \mathrm{wt} \%$, PVA filled all the pore networks, and the light transmittance was the highest. When that of PVA was greater than $20 \mathrm{wt} \%$, the excess PVA 
adhered to the surface, increasing the membrane thickness, and the transparency of the composite membrane began to decline.

Other impregnation solutions, such as epoxy resin or PMMA, can also improve the light transmittance of the electrospun fibrous membrane. Liao et al. [78] used thermoset epoxy resin and curing agent as the impregnation matrix. Uniaxially oriented as-spun cellulose nanofibers were soaked in the above mixed solution and solidified at a certain temperature. After the treatment, the membrane with a light transmittance of $88-92 \%$ was developed. Wu et al. [55] compounded an opaque PAN fibrous membrane and PMMA impregnated solution by solution dipping. The optical transparency of the PAN fibrous membrane was improved, and the light transmittance was up to $90 \%$ in the visible light range. Carboxylated multi-wall carbon nanotubes (MWCNTs-COOH)/PVA nanofibers prepared by direct electrospinning exhibited hydrophilicity and swelling properties. Therefore, the structure of the fibrous membrane was changed due to the aqueous solution dipping and nanofibers swelling to obtain a transparent membrane with a dense pore-free structure (as shown in Figure 7). Its transmittance reached 71\% [79].

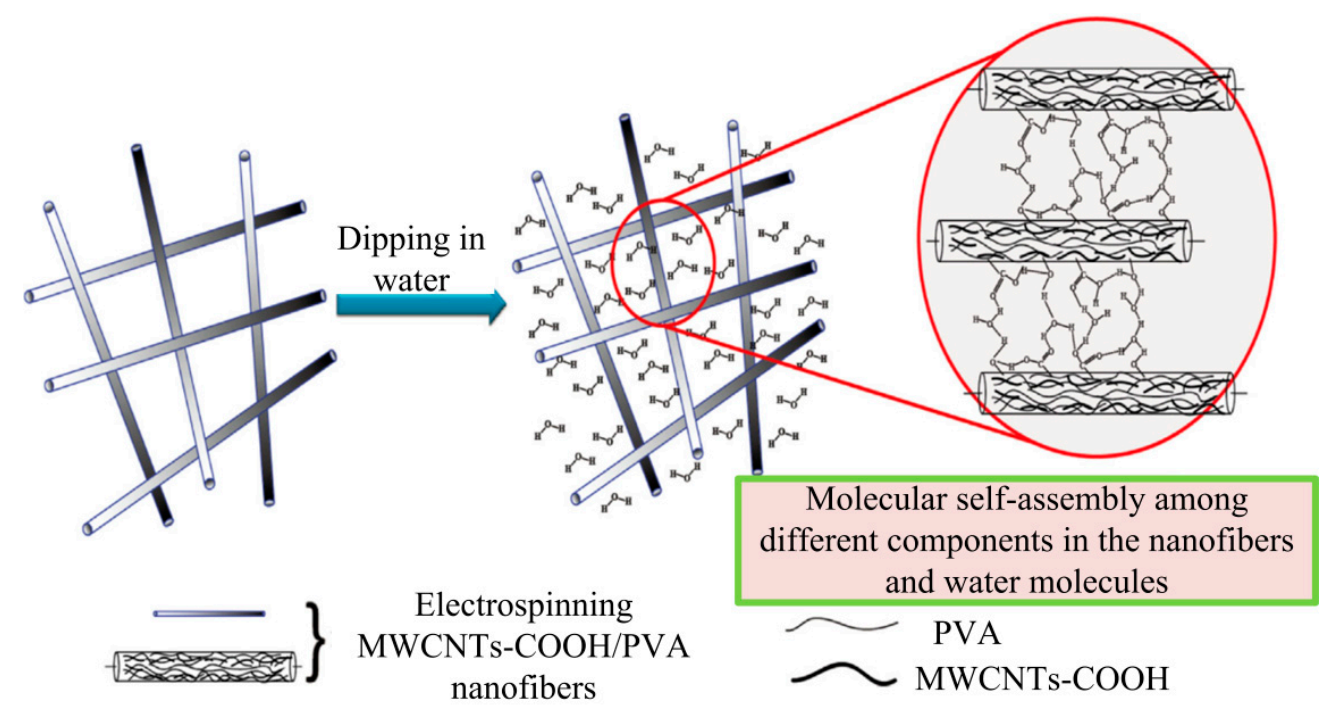

Figure 7. Scheme of self-assembly of transparent conductive composite films from nanofibers (Adapted from [79]).

In addition, the heated solvent vapor as an alternative dipping candidate, the transparent fibrous membrane can be obtained by the solvent evaporation treatment. Ma et al. [80] prepared a sandwich structured fibrous membrane composed of PCL and shellac. It has good mechanical properties and light transmittance after being treated with ethanol steam, which can be used for drug release in skin care.

\subsection{Heat Treatment after Electrospinning}

\subsubsection{Hot Pressing after Electrospinning}

Under certain temperature and pressure conditions, an electrospun fibrous membrane and other matrix materials are pressed to form composite membrane. The as-spun fiber is distributed in other materials as a dispersion phase. After removing pressure, a highly transparent composite fibrous membrane is obtained. Hot pressing can promote the material to fill the gap between the fibers. It can also reduce the light loss in the pores and therefore improve the light transmittance. Moreover, hot pressing between the two fibrous membranes but not the fibrous membrane/matrix materials can also be conducted. Kurokawa and Hotta [81] used electrospinning to prepare stereocomplex polylactide (scPLA) reinforced poly(l-lactide) (PLLA), and they obtained the self-reinforced PLA with a light transmittance of more than $75 \%$ by hot pressing. PLLA was infiltrated into an sc-PLA nanofibers membrane after melting at high temperature, filling the gap between sc-PLA fibers and improving the light transmittance. 
In order to avoid the decrease of light transmittance caused by crystallization, the fibrous film was quenched in liquid nitrogen immediately after compression molding to reduce the effect of secondary crystallization on the light transmittance. Lu et al. [82] prepared the thermochromic hydrophobic transparent nanocomposites by electrospinning and hot pressing, using PMMA and $\mathrm{VO}_{2}$ nanoparticles as raw materials. Li et al. [83] prepared a Cr/PA-6/PMMA ternary system electrospun fibrous membrane with significantly improved tensile strength and fracture toughness by hot pressing. During the preparation process, PA-6 was dissolved in $\mathrm{Cr} /$ hexafluoroisopropanol (HFIP) solution and then mixed with PMMA for electrospinning. PMMA fibers were fused to form a continuous matrix phase, and Cr/PA- 6 as the reinforcement phase improved the mechanical properties of the composite fibrous. Compared with the unreinforced pure PMMA, the transparency loss of the composite nanofibrous membrane was less than $10 \%$, and the transmittance of the membrane was still above 70\%. An et al. [84] prepared different proportion nylon-6,6 and cyclobutylene terephthalate (CBT) composite membranes by hot pressing. The results showed that the transmittance of the nanocomposite film with $76 \%$ CBT was the highest, because CBT, as a continuous matrix phase, filled the gap between nanofibers, resulting in a sharp reduction in the surface roughness of the composite fibrous film, avoiding light scattering and thus improving the transparency of the composite [74]. Due to temperature and pressure, hot pressing sometimes makes the material melting and cross-linking, forming a dense fibrous membrane.

Jiang et al. [85] immersed the electrospun PA-6 nanofibrous membrane in different concentrations of melamine formaldehyde (MF) aqueous solution and then prepared the fibrous membrane material by hot pressing. The PA-6/MF composite fibrous membrane was constructed by polymerization and cross-linking of MF around nylon- 6 nanofibers under hot pressing. The effect of the increase of PA-6 fibers content on the transmissivity of the composite was also investigated. The higher the fibers content, the lower the transmissivity of the fibrous membrane.

\subsubsection{Annealing after Electrospinning}

Annealing is a process of heat treatment in which the material is exposed to high temperature for a period of time and then cooled slowly. As a common means of heat treatment, the annealing process is widely used to eliminate the defects inside the metal [86], so as to improve the performance of the material. This method also plays a certain auxiliary role in improving the optical transparency of polymer materials.

Polyvinylpyrrolidone (PVP), a non-ionic polymer compound, is applied for the electrode materials preparation as an electrospun nanofibers matrix. Yoon and Kim [87] fabricated the PVP/ITO (indium tin oxide) as-spun membrane by annealing. The ITO solution was mixed with the PVP solution and then electrospun to obtain as-spun nanofibers, which were heat-treated by an IR furnace at $450{ }^{\circ} \mathrm{C}$ for $2 \mathrm{~h}$. The fibrous film with a light transmittance of more than $90 \%$ was obtained. Ning et al. [88] also selected PVP as an as-spun matrix and silver nitrate $\left(\mathrm{AgNO}_{3}\right)$-doped $\mathrm{Zn}\left(\mathrm{NO}_{3}\right)_{2}$ as an additive to fabricate the fibrous membrane with a cross-arrangement pattern. After annealing, the optical transparent Ag-doped $\mathrm{ZnO}$ nanofibers were obtained. Lamastra [89] et al. directly electrospun nickel acetate and PVP electrospinning precursor solution on sputtering nickel and nickel oxide film and then obtained the transparent and conductive $\mathrm{NiO}$ nanofibrous film by annealing in the air in the temperature range of $400-500{ }^{\circ} \mathrm{C}$. The transmittance of nickel oxide film increased from $54 \%$ to $75 \%$ by annealing. In addition, Cherpinski et al. [90] electrospun poly ( $\beta$-hydroxybutyrate) (PHB) nanofibrous film and explored the effect of annealing time and cooling method on the optical properties of PHB fibers. The experimental results showed that the minimum annealing temperature for producing uniform transparent film was $160{ }^{\circ} \mathrm{C}$. Wagner et al. [91] also adopted PHB as raw materials to obtain as-spun PHB-/PVA fibers and then dried them thoroughly and annealed them to obtain an ultra-thin fibrous membrane with a thickness of $173 \pm 4 \mu \mathrm{m}$. This transparent material had potential applications in the delivery of bioresponsive drugs. Furthermore, 
Ji [92] made a surface modification on electrospinning epoxy nanofibers. The cellulose nanofibers (CNF) were sprayed on the epoxy nanofibers surface by air gun, and the hybrid film was obtained by annealing at $90^{\circ} \mathrm{C}$. The epoxy resin was polymerized by exposure to ultraviolet radiation. Compared with the original CNF film, the light transmittance of the hybrid film was improved significantly from $77 \%$ to $88 \%$, which was due to the fact that compared with the CNF nanofibrous film, there were fewer holes in the hybrid film, resulting in a dense accumulation structure and significantly reduced light scattering (as shown in Figure 8). Meanwhile, compared with the original epoxy resin, the mechanical properties of the CNF hybrid film were also significantly improved due to the formation of high-strength carbon fibers. Shin [93] et al. fabricated moiré-fringeless TCFs with good optoelectrical characteristics and excellent thermal stability using a single-pass printed random serpentine network of medium-field electrospun silver microfibers (AgMFs), which would be used as flexible electronic devices. A transparent graphene skin electrode was also fabricated by annealing after electrospinning [94]. The precursor was prepared by dissolving styrene ethylene butylene styrene (SEBS), $\mathrm{CuCl}_{2}$, and phenolic resin (PR) into tetrahydrofuran (THF) solvent. A transparent graphene skin electrode was obtained after annealing for half an hour at $600{ }^{\circ} \mathrm{C}$. Its transparency could reach $83 \%$.

a CNF spraying $\begin{gathered}\text { Epoxy } \\ \text { electrospining }\end{gathered}$

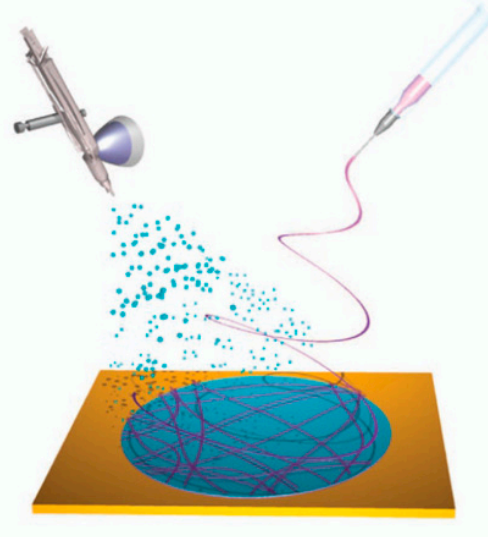

b

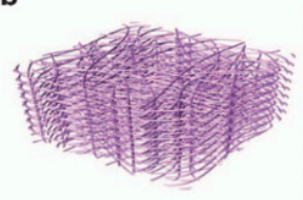

c

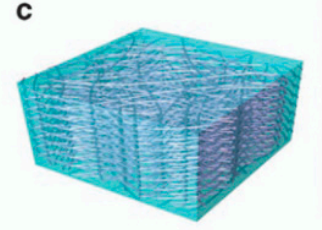

d

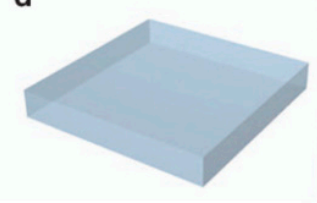

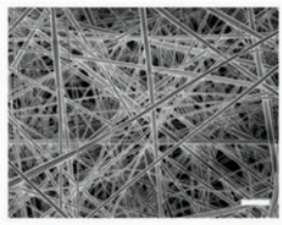
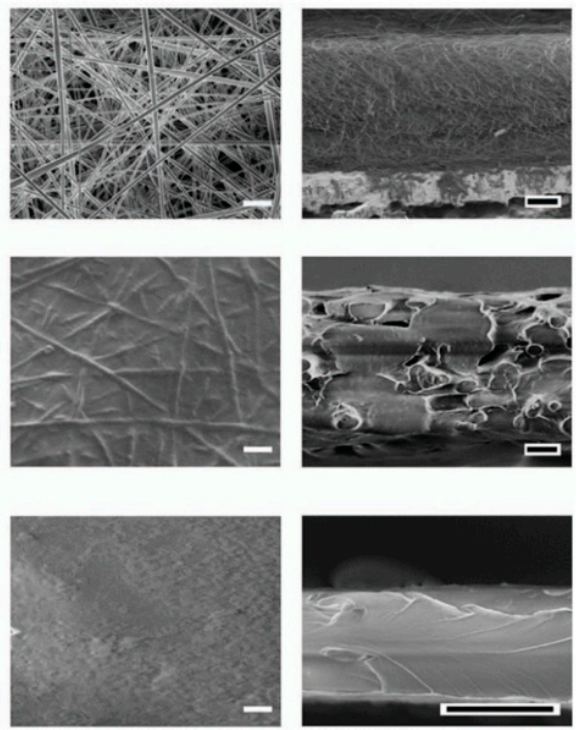

Figure 8. Preparation of the cellulose nanofibers (CNF) hybrid film. (a) A schematic image of an electrospinning epoxy backbone and spraying CNF fillers simultaneously. Schematics and scanning electron microscopy (SEM) images (top and cross-sectional views) of (b) the electrospun three-dimensional (3D) epoxy nanoweb structure, (c) the CNF epoxy hybrid before hot pressing, and (d) the CNF-epoxy hybrid after hot pressing. White scale bars are $10 \mu \mathrm{m}$, and black scale bars are $20 \mu \mathrm{m}$. (Adapted from [92]).

Different from traditional conventional thermal annealing (CTA), microwave annealing was an emerging annealing method. Hong [95] applied microwave annealing to post treatment indium tin oxide (ITO) nanofibers fabricated by electrospinning. The process adopted vacuum rapid thermal annealing (RTA) at $300^{\circ} \mathrm{C}$ for $30 \mathrm{~s}$, and it increased the electron concentration and reduced the resistance, thereby improving the properties of ITO nanofibers.

\subsubsection{Thermal Treatment after Electrospinning}

The optical transparency of electrospun fibers also is improved by thermal treatment, such as heating and calcinations. Different from annealing, this kind of heat treatment takes a very short time and is mostly instantaneous heating. Mele et al. [96] obtained the poly(ethyl 2-cyanoacrylate) continuous fibers by electrospinning. After heat treatment on a hot plate at $150{ }^{\circ} \mathrm{C}$ for $20 \mathrm{~s}$, a transparent fibers texture coating was obtained, which 
has good antifouling function. Hsieh et al. [97] successfully electrospun $\mathrm{Ag}^{+}$containing nanofibers from the solution of polyacrylonitrile (PAN)/dimethylacetamide/tetraaniline (TeAN). After heat treatment at $500{ }^{\circ} \mathrm{C}$ for a short period of time, the nanofibers on glass slides were successfully transformed into highly transparent and conductive silver nanofibrous networks. Zhao et al. [98] also used PAN as as-spun raw materials and prepared the composite nanofibrous membrane with a light transmittance of $95 \%$ by electrospinning the precursor of PAN/PU and heat treated the composite nanofibrous membrane at $200{ }^{\circ} \mathrm{C}$ for $10 \mathrm{~min}$. Moreover, Cho and Kuo [99] prepared $\mathrm{ZnO}$ nanofibers doped with $\mathrm{Al}$ by electrospinning and heating. By adjusting the doping amount of $\mathrm{Al}$ in the fibrous membrane, the influence of $\mathrm{Al}$ content on fibrous particle size and optical/electrical properties were studied. The results showed that $2 \%$ nanofibers had the best electrical properties, and the light transmittance remained around $84 \%$.

\subsection{Electroless Deposition after Electrospinning}

Electroless deposition is a method to selectively catalyze the metallization of electrospun nanofibers in which the specific operation is inserting electrosensitizers into polymer electrospinning solutions in order to obtain metal nanofibrous materials [100]. Electroless deposition can achieve uniform coating and retain the large surface area inherent in small diameter fibers, without the need of current, ultra-high vacuum, or high temperature [101,102].

Hsu et al. [103] prepared metal nanofibrous network (MNWs) by electrospinning and electroless deposition, which was a transparent electrode material with excellent conductivity. Firstly, the electrospun $\mathrm{PVB} / \mathrm{SnCl}_{2}$ nanofibers were immersed in silver nitrate solution, and the electrospun fibrous membrane with a silver seed layer on the surface was obtained by chemical reduction. The silver seed layer was mainly to facilitate the subsequent electroless deposition process. The prepared nanofibers had $90 \%$ light transmittance and good electrical conductivity. Testa et al. [104] prepared junctionless metal nanowire network in this method of the combination of electrospinning and electroless deposition, and the whole process does not require thermal annealing or a vacuum environment. The light transmittance of preparation of metal nano fibrous network was as high as $90 \%$, and the photoelectric performance would be enough to replace indium tin oxide (ITO) and become transparent electrode materials, whose production cost is much lower than the ITO.

\subsection{Surface Modification after Electrospinning}

After the surface modification of the electrospun fibrous film, the new properties of the material were obtained without affecting the optical transparency, such as sputtering coating [105,106], layer-by-layer self-assembly (LBL) [107], in situ polymerization [75], electron beam deposition [108], spraying, etc.

Jo et al. [109] sputtered platinum (Pt) seeds onto the surface of PAN nanofibers by sputtering and coating and then adjusted the thickness of polymer nanofibers by copper plating on the surface. The self-melting junction formed by electroplating significantly reduced the contact resistance between the copper fibers. In the process of copper plating, the thickness of the fibrous film was controlled by adjusting the plating time to minimize the loss of light transmittance. The fibrous film had a light transmittance of about $90 \%$.

Recently, Jiang et al. [110] modified the surface of copper electrospun nanofibers (CuNFs) by the functionalization approach, namely chemical reduction, and obtained an Ag-coated core-shell structure nanofibrous membrane. The fibrous membrane had high transmittance and can be transferred to a flexible substrate to make a transparent conductive electrode (TCEs). The transparent conducting electrode based on a $\mathrm{Cu} / \mathrm{Ag}$ core-shell nano network had good flexibility, transparency, and conductivity, which could be used in new flexible LED devices and solar cells. Sue et al. [111] also adopted the functionalization approach to prepare carbon nanotube/copper $(\mathrm{CNT} / \mathrm{Cu})$ fibers after electrospinning. In order to improve the $\mathrm{CNT}-\mathrm{Cu}$ interactions, cysteine was grafted to the surface of CNTs, and it exhibited not only excellent optoelectrical properties but was also optically transpar- 
ent. Beregoi et al. [112] fabricated core-double shell nylon-ZnO/polypyrrole electrospun nanofibers by functionalization after electrospinng as well. Nylon $6 / 6$ nanofibers were obtained through electrospinning and then were functionalized with $\mathrm{ZnO}$ by a sol-gel process. Furthermore, the $\mathrm{ZnO}$-coated networks had the deposition of a polypyrrole layer as an electrode to cover the nylon- $\mathrm{ZnO}$ nanofibers by electrodeposition. The unique core-shell nanofibers were highly transparent and flexible with a wide range of applications.

An et al. [113] prepared a core-shell $\mathrm{Cu} / \mathrm{Ni}$ electrode with high conductivity and corrosion resistance by electrospinning and electroplating. Firstly, PAN nanofibers were prepared by electrospinning, and then $\mathrm{Cu}$ and $\mathrm{Ni}$ were electroplated on the nanofibrous membrane in turn. Not only did the $\mathrm{Cu} / \mathrm{Ni}$ nanofibers haved high bending resistance and but also theits light transmittance was as high as $93 \%$, which could be used as a transparent heater.

\section{Application of Transparent Electrospun Fibrous Membrane}

\subsection{Alcohol Dipstick}

As a fairly new application area, rapid visual alcohol dipstick has just emerged in the transparent as-spun membranes application. Recently, the design of alcohol testing devices has attracted the attention of researchers due to the large number of traffic accidents caused by drunk driving. Our group [114] proposed a simple and straightforward method to fabricate electrospun poly (lactic acid)/polyvinylidene fluoride (PLA/PVDF) membrane and studied its transparency wetted by alcohol, which exhibited superior transparency, exceeding $90 \%$. The high transmittance was realized by the approximation of refractive index between the fibers and alcohol penetrated in the pore of the membrane. In comparison with traditional alcohol testing devices, this PLA/PVDF alcohol dipstick was reusable and more responsive to alcohol.

\subsection{Air Purification}

The air purification capacity and efficiency of electrospun fibers can be adjusted by controlling the diameter of the fibers, and the adsorption capacity of polar nanofibers to particulate pollutants is better than that of non-polar nanofibers [14]. As a result of its unique optical property, a transparent fibrous membrane can make light pass through an electrospun membrane effectively, further expanding the application of an electrospun fibrous membrane in PM2.5 adsorption [115]. Recently, Chen et al. [10] studied the influence of the diameter of electrospun TPU fibers on the filtration efficiency. By changing the concentration of TPU in polymer solution, the average diameter of TPU nanofibers increased from $0.14 \pm 0.06 \mu \mathrm{m}$ to $0.82 \pm 0.22 \mu \mathrm{m}$. The optimized TPU nanofibrous membrane can effectively remove $\mathrm{PM}_{2.5}$ from the air. Its efficiency was up to $98.92 \%$ and its service life was longer than the commercial filters on sale. Liu et al. [116] developed the PMMA/polydimethylsiloxane (PDMS) super hydrophobic layer and chitosan super hydrophilic layer of double-layer electrospun fibrous membrane materials, with a light transmittance of $86 \%$. Even after $100 \mathrm{~h}$ of testing in the air atmosphere with $\mathrm{PM}_{2.5}>3000 \mu \mathrm{gm}^{-3}$, the capture efficiency of the fibrous membrane for $\mathrm{PM}_{2.5}$ was still higher than $98.23 \%$, as shown in Figure 9. Liang et al. [117] prepared a transparent TPU air filter with a rotating bead spinel, and the removal efficiency of $\mathrm{PM}_{2.5}$ could be as high as $99.654 \%$. The durability of the air filter had also been greatly improved. After 10 times of filtration, it was found that the removal efficiency of $\mathrm{PM}_{2.5}$ only decreased by $1.6 \%$. The transparent electrospinning fibrous material also had an important application in the anti-haze window screen. Du et al. [7] attached polyethylene terephthate (PET) to polyester mesh, and the solvent incomplete evaporation could enhance the combination of electrospun polyester nanofibers and polyester mesh, which also increased the number of micron-nanometer holes, improving the light transmittance of window screens; the removal effect of $\mathrm{PM}_{2.5}$ was as high as $87 \%$. 


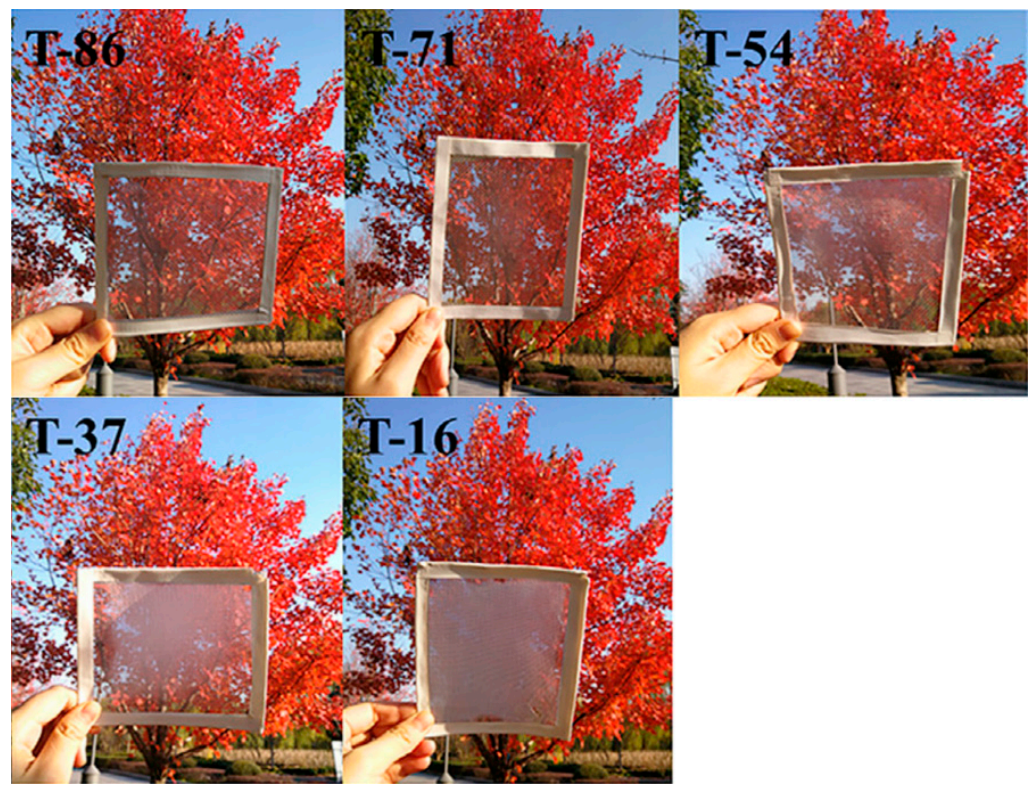

Figure 9. Photographs of PDMS/PMMA-chitosan transparent air filters at different transparencies (adapted from [116]). PMMA: polymethyl methacrylate.

An ultra-thin nanofibrous membrane was prepared by electrospinning PVP aqueous solution. In order to prevent the ultra-thin fibrous membrane from being easily damaged by accidental air movement or a stray electric field, Mikheev et al. [118] manufactured the water-soluble nanofilters for collecting biological micro- and nano-aerosols by electrospinning PVP solutions in different solvent mixtures. The electrospun PVP nanofibers were neutralized with a cloud of small counter-ions generated by electrospraying a volatile solvent. The nanoparticle with a diameter of only 0.03 to $0.05 \mu \mathrm{m}$ can be collected by the fibrous membrane.

\subsection{Self-Cleaning Materials}

The self-cleaning material can keep itself clean on a wide variety of environments, and it has multiple functions such as antifouling, deodorizing, and antibacterial. According to the different wettability of water, self-cleaning materials can be divided into superhydrophobic and superhydrophilic materials. These two types of materials can clean themselves according to the interaction with water [119]. The self-cleaning characteristics of superhydrophobic materials are determined by their high contact angle with water, which makes water form spherical droplets on its surface that are easy to roll away with dust and dirt [120]. On the contrary, on the super hydrophilic surface, water can diffuse completely and form a thin layer. In the presence of suitable photocatalysts, such as sunlight and water, most of the dirt on the surface of the material can be chemically decomposed.

Koo et al. [59] prepared a polystyrene/phenylsilsesquioxane (PS/PhSSQZ) nanofibrous membrane by electrospinning and thermal annealing, which had good environmental stability. The PS/PhSSQZ fibrous membrane had super hydrophobicity and lipophilicity due to its hierarchical fibrous structure and unique chemical properties. It could be used as a self-cleaning material in a hydrophobic structure coating, oil-water separation membrane, etc. After heat treatment at $600{ }^{\circ} \mathrm{C}$, the material still maintained its original fibrous structure, superhydrophobic property, and good stability. Li et al. [8] studied the hydrophilicity and photocatalytic properties of $\mathrm{DEA} / \mathrm{TiO}_{2}$ films prepared by electrospinning. The photocatalytic properties of this new $\mathrm{DEA} / \mathrm{TiO}_{2}$ film were studied by Congo red dye decay and silver ion reduction experiments. The experimental results showed that the $\mathrm{DEA} / \mathrm{TiO}_{2}$ film had an excellent photocatalytic activity. Through the measurement of water contact angle, it was proved that the water contact angle of the super hydrophilic coating was $2 \pm 1^{\circ}$, which had a self-cleaning function. 


\subsection{Biomedicine}

With the development of electrospinning technology and some breakthroughs in the medical field, the transparent fibrous membrane has been widely used in the biomedical field due to its simple production method and high specific surface area [121,122]. For example, the use of a highly transparent electrospinning fibrous membrane as wound dressing is conducive to doctors' intuitive inspection of wound conditions and avoids secondary damage caused by frequent opening of the dressing [123]. Compared with ordinary fibers, electrospun polymer fibers have better biocompatibility and can promote cell differentiation [124], so they can be used as a scaffold for cell and tissue culture. An electrospun transparent fibrous membrane is more convenient for observing the morphology and growth of cells compared with that of opaque, so as to avoid pollution caused by unnecessary turnover [125]. Jin et al. [126] obtained an electrospun membrane with a diameter less than $1 \mu \mathrm{m}$ by electrospinning the mixture of natural protein silk and polyethylene oxide (PEO), which was used as a biomaterial scaffold material for vascular transplantation or wound dressing. As a natural polymer material, cellular cellulose has good biocompatibility and high transparency, and it can be applied for tissue engineering scaffolds or medical implant materials $[127,128]$. Electrospun nanofibers based on cell cellulose (BC) promoted the growth and differentiation of tissue cells, which had a widespread application as a tissue cell growth scaffold [129] and wound-healing platform [130]. Kim et al. [131] found that BC-based electrospun nanofibers had high transparency, which were employed for use as nanopatches to treat traumatic tympanic membrane perforation. Ma et al. [80] electrospun a PCL/shellac transparent fibrous membrane, which had an excellent drug release performance. The drug release time and amount significantly increased after ethanol treatment, which met the utilization requirements in facial skin care and overnight medication.

After electrospinning and heat treatment, a poly(ethyl 2-cyanoacrylate) (PECA) fibrous membrane with optical transparency and good biocompatibility was prepared [96]. Cells adhered well to the above material for proliferation, which enhanced the metabolic activity and could differentiate in the myotube. These properties of the PECA fibrous membrane enabled it to be used as a protective layer for hip and knee joints, coronary stents, and heart valves, as well as for biomedical devices [132].

\subsection{Sensors}

Transparent sensor refers to a light-transmitting device that measures a specific substance and converts it into an output signal according to a certain rule. The development of a transparent sensor can meet specific needs and develop more extensive applications. At present, the research studies of transparent sensors mainly include chemical sensors that detect and monitor dangerous substances in the gas phase, protecting us from pollution and toxic gases [133]. Self-powered sensors convert wasted micromechanical energy into available electrical energy based on the principles of triboelectricity and piezoelectric [134-136]. Optical sensors for chromaticity detection, resistance sensors [137], temperature sensors [98], humidity sensors [138], and pressure sensors, etc. converting external stimuli into electronic signals also had been studied [139].

Duy et al. [133] prepared the elastic polyurethane electrospun nanofibrous multilayer sensor with chemical response, which was flexible and stretchable, by electrospun PU nanofibers and reductive polyethylene oxide (R-GO) by self-assembly (LBL), which was used for gas or steam detection. The R-GO/PU devices with four and five layers have excellent sensitivity and mechanical sustainability up to $50 \%$ of the strain under static and cyclic tensile tests. Najarzadekan and Sereshti [76] used PA-6 and 1, 10-phenanthroline (1, 10-Phen) as raw materials to prepare an optical sensor with a nanofibrous scaffold structure by electrospinning and impregnation. It could be used for the colorimetric determination of $\mathrm{Fe}^{2+}$ and ascorbic acid. Li et al. [140] prepared a serpentine silver nanofibrous elastomer (SNME) by electrospinning with polyvinyl butyral (PVB) and nano silver as raw materials. By adjusting the content of Ag nanoparticles and chemical deposition time, the 
photoelectric properties of SNME were optimized, and the films with high visible light transmittance of $81 \%$ and low resistance of $9.2 \Omega \cdot S^{-1}$ were obtained. After 1000 cycles of repeated stretching, SNME still had a good stretching performance. As a wearable resistance sensor, SNME was used to monitor the movement of finger joints. Qiu et al. [94] obtained highly graphitized phenolic resin electrospun fibers/single-layer graphene (GFG) fibrous membrane by electrospinning, annealing, and solvent evaporation. It had high electrical conductivity and $83 \%$ high light transmittance and could be used as a wearable medical sensor for effective skin surface monitoring of biological signals. The fibrous membrane mimicked the mechanical structure of a bird's nest and significantly enhanced the mechanical properties of the fibrous membrane.

The self-healing TPU nanofibrous film obtained by Choi et al. [141] was opaque. As time went on, the nanofibrous film became irreversibly transparent at room temperature through self-healing-induced interfibrillar fusion, leading to the appearance of a warning sign. It could be applied as a time sensor to detect the change of time and monitor the freshness of food, and it operated through an intrinsic physical response Compared with traditional sensors, electrospun fibrous sensors were more portable and breathable, and they effectively avoided the joint swelling [142] and inflammation [143] caused by wearing for a long time and health detection.

\subsection{Energy and Optoelectronics}

Transparent fibrous film has been widely studied in the field of optoelectronics, such as flexible transparent display screens [144], transparent electrodes [145-148], transparent light-emitting diodes [110], stretchable transparent heaters [149], etc. Transparent polymer nanofilms reinforced by fibrous can effectively replace indium tin oxide (ITO) as a new electrode material [150]. Wang et al. [151] used electrospun pan as a mask, polyethylene terephthalate (PET) and polydopamine (PDA) as a substrate, and metal Ag as a raw material to prepare metal mesh with super adhesion and mechanical strength. The silver grid (s-Ag) mainly provided high conductivity, while polymer PDA with strong adhesion provided mechanical flexibility. When the composite material was used as the electrode of a solar cell, the power conversion efficiency was $6.4 \%$, and it had superior mechanical stability and high conductivity. Matei et al. [105] electroplated the electrospun PMMA fibrous and prepared the $\mathrm{ZnO}$-coated PMMA fibrous membrane. The fibrous membrane had excellent photocatalytic properties and was used as a transparent electrode of the solar cell. He et al. [152] electrospun metal $\mathrm{Cu}$ nanofilms on rigid glass and flexible PET substrates. Except for its conductivity, the fibrous film also showed outstanding toughness, which withstood repeated transparent tape peeling and various bending tests and could be used as a flexible touch screen.

In order to improve the definition of structural metals due to a large scattering crosssection, which affects the application of electrospun metal fibers in touch screens and transparent electrodes, Kim et al. [153] carried out a surface oxidation treatment on electrospun silver nanofibers to form an $\mathrm{Ag} / \mathrm{Ag}_{2} \mathrm{O}$ core/shell structure. $\mathrm{Ag}_{2} \mathrm{O}$ had absorption capacity, which eliminated multiple moments in $\mathrm{Ag}$ nanowires and inhibited plasma scattering. The transmittance of $\mathrm{Ag} / \mathrm{Ag}_{2} \mathrm{O}$ was higher than that of bare $\mathrm{Ag}$ nanowires, and the transmittance was not less than $92 \%$ in the visible light range.

He et al. [154] prepared transparent conductive films with light transmittance of $90 \%$ at $550 \mathrm{~nm}$ by electrospinning, annealing, and etching using reduced graphene oxide (rGO) and PVA. In general, when the film thickness increased, the conductivity increased, but the transmittance decreased. The method of etching with electrospun PVA fibrous film effectively balanced the relationship between conductivity and transmittance of the rGO conductive nanobelt network. Huang et al. [155] immersed the polyurethane electrospinning nanofibers membrane into the mixture of silver phosphate nanometer particles and graphene nano solution (AgNP-GNS) to construct two-dimensional conductive networks, obtaining self-assembly AgNP-GNS/PU film, which had great potential in the field of transparent flexible electrodes. In this research, the Ag nanoparticle layer had little effect 
on light transmittance. The wavelength of visible light was comparable to that of light scattering between the nanofiber gaps, which caused light scattering, so through heating the PU nanofibers until melted, the PU nanofibers gap decreased, and the high light transmittance nanofibrous membrane was obtained (as shown in Figure 10). Tian et al. [156] prepared a $\mathrm{ZnO}-\mathrm{SnO}_{2}$ nanofibrous membrane by electrospinning, and it was used in transparent devices as a high-performance fully transparent photodetector, which had high UV sensitivity, a photoelectric dark current ratio, and a fast response speed. Firstly, the $\mathrm{Zn}$ $\left(\mathrm{NO}_{3}\right)_{2}$ and $\mathrm{SnCl}_{2}$ were electrospun with the help of polymer polyvinylpyrrolidone (PVP). The transparent fibrous film was calcined to remove the organic components to obtain zinc-tin oxide nanofibers, and the light transmittance was further improved.
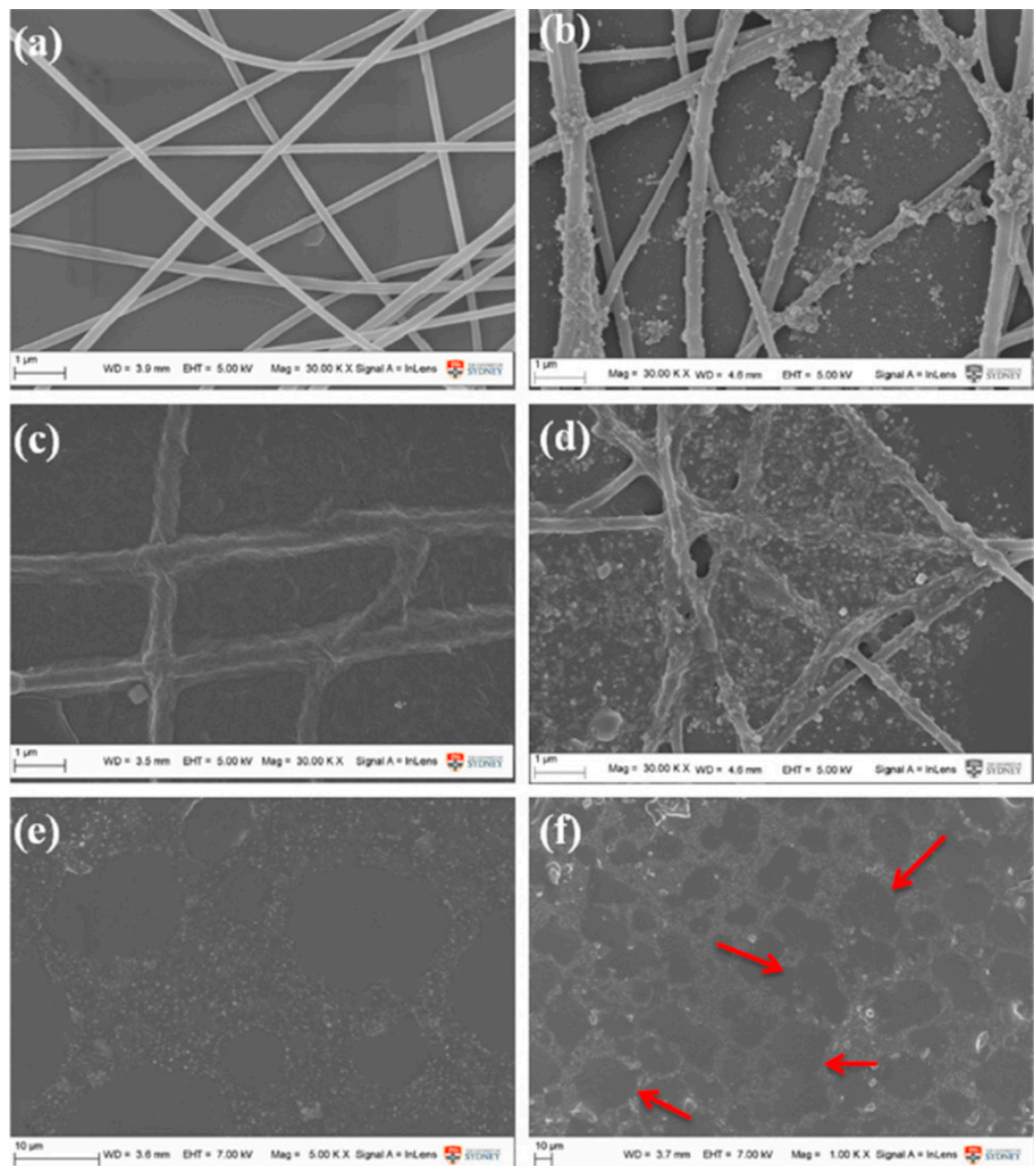

Figure 10. High-resolution SEM images of polyurethane (PU) nanofibrous mats. (a) Electrospun for 180 s. PU nanofibrous electrospun for $180 \mathrm{~s}$ dipped with (b) silver phosphate nanometer particles (AgNPs), (c) graphene nano solution (GNSs), (d) AgNPs-GNSs (5:1) and (e) AgNPs-GNSs (3:1) after melting. (f) shows SEM micrograph of (e) under low magnification. (Adapted from [155]).

\subsection{Oil-Water Separation}

Electrospinning fibrous membrane materials are widely used in the field of oil-water separation due to their high porosity, high specific surface area, and good water permeability $[59,157]$. The ideal oil-water separation membrane with super hydrophobic and high lipophilic could achieve high oil-water separation efficiency. Zhang et al. [158] decorated an UV-resist and transparent coating consisting of PDMS and ZnO on a highly stable and self-standing polyimide. The obtained fibrous membrane had the characteristics of excellent UV resistance and 99\% oil-water separation efficiency, and the transmittance was as high as $93 \%$. Herein, PDMS was mainly used to enhance the wettability of PI, while increasing the oil-water separation efficiency of PI fibrous membrane. $\mathrm{ZnO}$ provided an anti ultraviolet effect and prolonged the service life of the polymer fibrous membrane. 
Ma et al. [159] also used PDMS to treat PI to obtain a PI fibrous membrane with significantly enhanced oil-water separation efficiency. Different from Zhang's research, the anti-ultraviolet property was mainly provided by the tannin of plant polyphenols, and tannic acid had an inherent ultraviolet absorption capacity. Therefore, the service life of the modified PI fibrous membrane was prolonged and it had high transparency.

\subsection{Food Packaging}

Food packaging materials are required to be safe and non-toxic. Their water resistance, gas barrier, and mechanical properties should be excellent as well. In general, the electrospun fibers has a large aspect ratio, which establishes a tortuous path to provide a channel for the diffusion of oxygen molecules and performs as a reduced barrier. However, some researchers relied on the establishment of hybrid fibers that blocked the oxygen diffusion path and performed as an excellent gas barrier, which met the requirements of food packaging materials $[160,161]$.

In order to meet the material safety requirements of food packaging, safe and nontoxic natural polymers are usually selected, such as oregano essential oil for its significant antibacterial effect [162]. Lopez produced packaging films of poly(3-hydroxybutyrateco-3-hydroxyvalerate) (PHBV) with alpha- and gamma-cyclodextrins ( $\alpha$-CD and $\gamma$-CDs) containing oregano essential oil (OEO). After annealing, transparent films with enhanced antioxidant and antibacterial properties were obtained, which prolonged the time of food preservation effectively when used in food packaging. Poly (3-hydro-xybutyrate) (PHB) is a non-toxic, harmless, and biocompatible material, which is widely used in food packaging. After annealing, the PHB film was uniform and transparent. The oxygen permeability of the film was significantly reduced, and the water resistance of the film was also significantly improved [90].

A nanofibrous membrane with antibacterial property is also a major development direction of food packaging materials. Food poisoning is usually caused by histamine produced by food-borne bacteria such as Staphylococcus aureus, Proteus and Salmonella paratyphi A. Erbay et al. [163] prepared a submicron PCL nanofibrous membrane filled with nano zeolite and silica $\left(\mathrm{SiO}_{2}\right)$ by electrospinning, and then heat-treated it to obtain a transparent fibrous membrane with significantly improved mechanical properties, which effectively captured histamine produced by Staphylococcus aureus and paratyphoid bacillus.

\subsection{Anti-Icing Coating}

The anti-icing coating is an effective method to prevent icing and facilitate de-icing. The anti-icing coating is not only superhydrophobic and ice repellent $[164,165]$ but also cold resistant in a low-temperature environment $[166,167]$. After improving the surface roughness, porous electrospun fibers are more easily prepared as a superhydrophobic surface, which is effective for anti-icing coating. Tas et al. [168] injected lubricants matching its refractive index into electrospun PVDF-co-HFP, such as poly (chlorotrifluoroethylene) (PcTFE) or silicone oil, and the light transmittance of the fibrous film was as high as $90 \%$. The results showed that the lubricant provided a smooth surface for the electrospun fibrous film, and the ice adhesion was significantly reduced.

\subsection{Anti-Corrosion Material}

Coatings, corrosion-resistant materials, and corrosion inhibitors are usually the main strategies to solve the problem of steel corrosion [169]. Metal corrosion is caused by the direct contact between metal and water, oxygen, or acid solution, so the effective method of metal corrosion prevention is to isolate the metal itself from contacting with water, oxygen, or acid solution $[170,171]$. Usually, an anti-corrosion coating with a superhydrophobic surface could effectively reduce the contact range between the metal matrix and corrosion solution [172]. Therefore, some self-healing material due to its specific property could be applied as an anti-corrosion material, which not only has good anti-corrosion effect but also has significantly enhanced durability [173]. An et al. [174] prepared two core-shell 
structured fibers by coaxial electrospinning. One of them was liquid resin monomer in the core and PAN in the shell, and the other was a liquid-curing agent in the core and PAN in the outer layer. These two kinds of fibers were intertwined and embedded into PDMS or SU-8 to form a transparent flexible self-healing composite, which was covered on the surface of the metal. When the surface was scratched, the liquid curing agent and resin were released from the fibers core, polymerized, and repaired the damaged surface to protect the metal from corrosion.

Table 1. Materials, preparation methods, film thickness, average diameter, and application fields of nanofibrous films with light transmittance above $90 \%$.

\begin{tabular}{|c|c|c|c|c|c|c|}
\hline Material & $\begin{array}{c}\text { Light } \\
\text { Transmittance }\end{array}$ & Thickness & $\begin{array}{l}\text { Average } \\
\text { Diameter }\end{array}$ & Preparation Method & Application & Citation \\
\hline CNWs/epoxy resin & $92 \%$ & $0.43 \pm 0.03 \mathrm{~mm}$ & & $\begin{array}{l}\text { Dipping after } \\
\text { electrospinning }\end{array}$ & reinforcing material & {$[78]$} \\
\hline PAN/PMMA & $90 \%$ & $0.1-0.4 \mathrm{~mm}$ & $550 \mathrm{~nm}$ & $\begin{array}{l}\text { Dipping after } \\
\text { electrospinning }\end{array}$ & $\begin{array}{l}\text { windshields for } \\
\text { fast-moving objects }\end{array}$ & {$[55]$} \\
\hline PA-6/TPU & $>90 \%$ & & $163 \mathrm{~nm}$ & $\begin{array}{l}\text { Casting after } \\
\text { electrospinning }\end{array}$ & & {$[64]$} \\
\hline ITO/PVP & $95 \%$ & $75.7 \mathrm{~nm}$ & $188.0 \pm 29.6 \mathrm{~nm}$ & $\begin{array}{l}\text { Annealing after } \\
\text { electrospinning }\end{array}$ & $\begin{array}{c}\text { optoelectronic and } \\
\text { sensing applications. }\end{array}$ & [87] \\
\hline $\mathrm{PAN} / \mathrm{PU}$ & $>95 \%$ & & & $\begin{array}{l}\text { Thermal treatment } \\
\text { after electrospinning }\end{array}$ & temperature monitor & [98] \\
\hline $\mathrm{Cu}$ & $90 \%$ & & & $\begin{array}{l}\text { Surface modification } \\
\text { after electrospinning }\end{array}$ & transparent heater & [109] \\
\hline $\begin{array}{c}\mathrm{ZnO} / \\
\text { PDMS-PI }\end{array}$ & $93 \%$ & & & $\begin{array}{l}\text { Surface modification } \\
\text { after electrospinning }\end{array}$ & $\begin{array}{l}\text { oil-water separation } \\
\text { membrane }\end{array}$ & {$[158]$} \\
\hline $\mathrm{Ag} / \mathrm{Ag}_{2} \mathrm{O}$ & $92 \%$ & & & $\begin{array}{l}\text { Surface modification } \\
\text { after electrospinning }\end{array}$ & $\begin{array}{l}\text { optoelectronic } \\
\text { applications }\end{array}$ & {$[153]$} \\
\hline $\mathrm{Cu} / \mathrm{Ni}$ & $93 \%$ & & $4.75 \mu \mathrm{m}$ & $\begin{array}{l}\text { Surface modification } \\
\text { after electrospinning }\end{array}$ & transparent heater & [113] \\
\hline rGO/PVA & $90 \%$ & & & $\begin{array}{l}\text { Annealing after } \\
\text { electrospinning }\end{array}$ & conductive film & {$[154]$} \\
\hline PDMS/PAN & $90 \%$ & & & Direct electrospinning & $\begin{array}{l}\text { self-healing } \\
\text { anticorrosive material }\end{array}$ & {$[174]$} \\
\hline $\begin{array}{l}\mathrm{AgNW} \\
\mathrm{CuNW}\end{array}$ & $90 \%$ & & $70 \mathrm{~nm}$ & $\begin{array}{l}\text { Electroless deposition } \\
\text { after electrospinning }\end{array}$ & electrical conductivity & {$[103]$} \\
\hline $\mathrm{Cu}$ & & & & $\begin{array}{l}\text { Electroless deposition } \\
\text { after electrospinning }\end{array}$ & transparent electrode & {$[104]$} \\
\hline
\end{tabular}

\section{Conclusions}

On the basis of the present research situation and prospects, a facile electrospinning strategy was implemented to fabricate a fibrous membrane for achieving an enhanced transparency, which had a wide application prospect in optical devices, flexible display screens, light-emitting diodes, filtering, self-cleaning, cell growth scaffolds, wound dressing, and drug release carriers. Investigating the light transmission mechanism of electrospinning fibers, research studies based on the materials selection, controllable microstructure, and topological arrangement were conducted, and several methods were employed to provide effective solutions to obtain homogenous membranes with comparable refractive indexes beneficial for light propagation. However, some restrictions still exist, including the reduced porosity and thickness of the fibrous membrane, which destroys its internal structure and mechanical properties. Therefore, to balance the methods/parameters and thickness of the fibrous membrane with the mechanical properties, the thermal properties and stability of membrane materials still need to be explored by researchers. 
Author Contributions: Conceptualization, Y.X. and J.H.; Software, H.L.; Validation, Y.X. and R.T.; Investigation, R.T.; Resources, Y.X.; Writing-Original Draft Preparation, H.L.; Writing-Review and Editing, J.H.; Visualization, Y.X.; Supervision, J.H.; Funding Acquisition, J.H. All authors have read and agreed to the published version of the manuscript.

Funding: This research was funded by the national natural science Foundation of China (No. 51103058), 135 Science and Technology Project of Jilin Province Education Department (No. JJKH20190139KJ), Jilin Province Science and Technology Development Plan Project, and National Scholarship Council.

Institutional Review Board Statement: Not applicable.

Informed Consent Statement: Not applicable.

Data Availability Statement: The data presented in this study are available on request from the corresponding author.

Acknowledgments: The authors gratefully acknowledge the financial support of this work by the national natural science Foundation of China (No. 51103058), 135 Science and Technology Project of Jilin Province Education Department (No. JJKH20190139KJ), Jilin Province Science and Technology Development Plan Project, and National Scholarship Council.

Conflicts of Interest: The authors declare no conflict of interest.

\section{References}

1. Li, D.; Xia, Y. Electrospinning of nanofibers: Reinventing the wheel? Adv. Mater. 2004, 16, 1151-1170. [CrossRef]

2. Wan, Z.; Wang, L.; Yang, X.; Guo, J.; Yin, S. Enhanced water resistance properties of bacterial cellulose multilayer films by incorporating interlayers of electrospun zein fibers. Food Hydrocoll. 2016, 61, 269-276. [CrossRef]

3. Chen, H.-T.; Lin, H.-L.; Chen, I.-G.; Kuo, C. Conducting silver networks based on electrospun poly(methyl methacrylate) and silver trifluoroacetate. ACS Appl. Mater. Interfaces 2015, 7, 9479-9485. [CrossRef]

4. Wang, Z.; Zhang, L.; Liu, J.; Li, C. A flexible bimodal sensor based on an electrospun nanofibrous structure for simultaneous pressure-temperature detection. Nanoscale 2019, 11, 14242-14249. [CrossRef]

5. Bergshoef, M.M.; Vancso, G.J. Transparent nanocomposites with ultrathin, electrospun nylon-4,6 fiber reinforcement. Adv. Mater. 1999, 11, 1362-1365. [CrossRef]

6. Babu, K.J.; Kaur, G.; Biswal, L.; De, G.; Ghosh, H.N. Ultrafast charge delocalization dynamics of ambient stable CsPbBr 3 nanocrystals encapsulated in polystyrene fiber. Chemistry 2020, 27, 683-691. [CrossRef]

7. Du, L.; Zhang, Y.; Li, X.; Wang, J.; Chen, M.; Zuo, X.; Yang, W.; Yousefzadeh, M.; Ramakrishana, S.; Li, H. High performance anti-smog window screens via electrospun nanofibers. J. Appl. Polym. Sci. 2019, 137. [CrossRef]

8. Li, F.; Li, Q.; Kim, H. Spray deposition of electrospun TiO2 nanoparticles with self-cleaning and transparent properties onto glass. Appl. Surf. Sci. 2013, 276, 390-396. [CrossRef]

9. Kim, J.I.; Kim, J.Y.; Park, C.H. Fabrication of transparent hemispherical 3D nanofibrous scaffolds with radially aligned patterns via a novel electrospinning method. Sci. Rep. 2018, 8, 1-13. [CrossRef]

10. Chen, R.; Zhang, X.; Wang, P.; Xie, K.; Jian, J.; Zhang, Y.; Zhang, J.; Yuan, Y.; Na, P.; Yi, M.; et al. Transparent thermoplastic polyurethane air filters for efficient electrostatic capture of particulate matter pollutants. Nanotechnology 2019, $30,015703$. [CrossRef] [PubMed]

11. Busuioc, C.; Evanghelidis, A.; Galatanu, A.; Enculescu, I. Direct and contactless electrical control of temperature of paper and textile foldable substrates using electrospun metallic-web transparent electrodes. Sci. Rep. 2016, 6, 34584. [CrossRef] [PubMed]

12. Huang, L.; Nagapudi, K.; Apkarian, R.P.; Chaikof, E.L. Engineered collagen-PEO nanofibers and fabrics. J. Biomater. Sci. Polym. Ed. 2001, 12, 979-993. [CrossRef]

13. Fuh, Y.K.; Lien, L.-C. Pattern transfer of aligned metal nano/microwires as flexible transparent electrodes using an electrospun nanofiber template. Nanotechnology 2013, 24, 055301. [CrossRef]

14. Xu, J.; Liu, C.; Hsu, P.-C.; Liu, K.; Zhang, R.; Liu, Y.; Cui, Y. Roll-to-roll transfer of electrospun nanofiber film for high-efficiency transparent air filter. Nano Lett. 2016, 16, 1270-1275. [CrossRef] [PubMed]

15. Cui, J.; Lu, T.; Li, F.; Wang, Y.; Lei, J.; Ma, W.; Zou, Y.; Huang, C. Flexible and transparent composite nanofibre membrane that was fabricated via a "green" electrospinning method for efficient particulate matter 2.5 capture. J. Colloid Interface Sci. 2020, 582, 506-514. [CrossRef] [PubMed]

16. Whitted, T. An improved illumination model for shaded display. Commun. ACM 1980, 23, 343-349. [CrossRef]

17. Hendy, S.C. Light scattering in transparent glass ceramics. Appl. Phys. Lett. 2002, 81, 1171-1173. [CrossRef]

18. Fedorov, P.; Luginina, A.; Popov, A. Transparent oxyfluoride glass ceramics. J. Fluor. Chem. 2015, 172, 22-50. [CrossRef]

19. Berthier, T.; Fokin, V.M.; Zanotto, E.D. New large grain, highly crystalline, transparent glass-ceramics. J. Non-Cryst. Solids 2008, 354, 1721-1730. [CrossRef]

20. Tsukuma, K.; Yamashita, I.; Kusunose, T. Transparent 8 mol\% Y2O3-ZrO2(8Y) ceramics. J. Am. Ceram. Soc. 2008, 91, 813-818. [CrossRef] 
21. Krell, A.; Klimke, J.; Hutzler, T. Transparent compact ceramics: Inherent physical issues. Opt. Mater. 2009, 31, 1144-1150. [CrossRef]

22. Zhang, H.; Kim, B.-N.; Morita, K.; Yoshida, H.; Lim, J.-H.; Hiraga, K. Optimization of high-pressure sintering of transparent zirconia with nano-sized grains. J. Alloys Compd. 2010, 508, 196-199. [CrossRef]

23. Zhang, H.; Kim, B.-N.; Morita, K.; Yoshida, H.; Lim, J.-H.; Hiraga, K. Optical properties and microstructure of nanocrystalline cubic zirconia prepared by high-pressure spark plasma sintering. J. Am. Ceram. Soc. 2011, 94, 2981-2986. [CrossRef]

24. Miao, X.; Huo, X.; Liu, L.; Tang, S.; Guo, M.; Cheng, F.; Zhang, M. Crystallisation kinetics and structural stability of transparent $\mathrm{CaF}_{2}$ glass ceramics: Dependence of light transmittance on the amount of $\mathrm{CaF}_{2}$ added. Ceram. Int. 2020, 46, 15314-15324. [CrossRef]

25. Zhao, X.; Chao, X.; Wu, D.; Liang, P.; Yang, Z. Evaluation of birefringence contribution to transparency in (1-x)KNN$\mathrm{xSr}\left(\mathrm{Al}_{0.5} \mathrm{Ta}_{0.5}\right) \mathrm{O}_{3}$ ceramics: A phase structure tailoring. J. Alloys Compd. 2019, 798, 669-677. [CrossRef]

26. Zhang, K.; Li, W.; Zeng, J.; Deng, T.; Luo, B.; Zhang, H.; Huang, X. Preparation of $\left(\mathrm{La}_{0.2} \mathrm{Nd}_{0.2} \mathrm{Sm}_{0.2} \mathrm{Gd}_{0.2} \mathrm{Yb}_{0.2}\right)_{2} \mathrm{Zr}_{2} \mathrm{O}_{7}$ high-entropy transparent ceramic using combustion synthesized nanopowder. J. Alloys Compd. 2020, 817, 153328. [CrossRef]

27. Zhao, X.; Chai, Q.; Chen, B.; Chao, X.; Yang, Z. Improved transmittance and ferroelectric properties realized in KNN ceramics via SAN modification. J. Am. Ceram. Soc. 2018, 101, 5127-5137. [CrossRef]

28. Zhang, M.; Yang, H.; Li, D.; Lin, Y. Excellent energy density and power density achieved in $\mathrm{K}_{0.5} \mathrm{Na}_{0.5} \mathrm{NbO}_{3}$-based ceramics with high optical transparency. J. Alloys Compd. 2020, 829, 154565. [CrossRef]

29. Belyaev, A.; Basyrova, L.; Sysoev, V.; Lelet, M.; Balabanov, S.; Kalganov, V.; Mikhailovski, V.; Baranov, M.; Stepanidenko, E.; Vitkin, V.; et al. Microstructure, doping and optical properties of $\mathrm{Co}^{2+}: \mathrm{ZnAl}_{2} \mathrm{O}_{4}$ transparent ceramics for saturable absorbers: Effect of the $\mathrm{ZnF}_{2}$ sintering additive. J. Alloys Compd. 2020, 829, 154514. [CrossRef]

30. Chen, X.; Liu, X.; Feng, Y.; Li, X.; Chen, H.; Xie, T.; Kou, H.; Kučerková, R.; Beitlerová, A.; Mihóková, E.; et al. Microstructure evolution in two-step-sintering process toward transparent $\mathrm{Ce}:(\mathrm{Y}, \mathrm{Gd})_{3}(\mathrm{Ga}, \mathrm{Al})_{5} \mathrm{O}_{12}$ scintillation ceramics. J. Alloys Compd. 2020, 846, 156377. [CrossRef]

31. Li, Q.L.; Cheung, S.W.; Wu, D.; Yuk, T.I. Optically transparent dual-band mimo antenna using micro-metal mesh conductive film for WLAN system. IEEE Antennas Wirel. Propag. Lett. 2017, 16, 920-923. [CrossRef]

32. Song, R.; Li, X.; Gu, F.; Fei, L.; Ma, Q.; Chai, Y. An ultra-long and low junction-resistance Ag transparent electrode by electrospun nanofibers. RSC Adv. 2016, 6, 91641-91648. [CrossRef]

33. Azuma, K.; Sakajiri, K.; Matsumoto, H.; Kang, S.; Watanabe, J.; Tokita, M. Facile fabrication of transparent and conductive nanowire networks by wet chemical etching with an electrospun nanofiber mask template. Mater. Lett. 2014, 115, 187-189. [CrossRef]

34. Wang, J.; Jiu, J.; Sugahara, T.; Nagao, S.; Nogi, M.; Koga, H.; He, P.; Suganuma, K.; Uchida, H. Highly reliable silver nanowire transparent electrode employing selectively patterned barrier shaped by self-masked photolithography. ACS Appl. Mater. Interfaces 2015, 7, 23297-23304. [CrossRef] [PubMed]

35. Kubwimana, J.L.; Kirsch, N.J.; Ziegler, C.; Kontopidis, G.; Turner, B. Dual-polarized 5.75 GHz optically transparent antenna arrays. IEEE Antennas Wirel. Propag. Lett. 2019, 18, 1512-1516. [CrossRef]

36. Lee, S.; Kim, S.-W.; Ghidelli, M.; An, H.S.; Jang, J.; Bassi, A.L.; Lee, S.-Y.; Park, J. Integration of transparent supercapacitors and electrodes using nanostructured metallic glass films for wirelessly rechargeable, skin heat patches. Nano Lett. 2020, 20, 4872-4881. [CrossRef]

37. Himeno, Y.; Matsuda, M.; Shida, K.; Matsuda, M. Dopant-free transparent $\mathrm{ZrO}_{2}$ with monoclinic structure produced by oxidation process using Zr metal. Scr. Mater. 2020, 187, 103-106. [CrossRef]

38. Jo, H.; Yang, J.-H.; Choi, S.-W.; Park, J.; Song, E.J.; Shin, M.; Ahn, J.-H.; Kwon, J.-D. Highly transparent and conductive oxidemetal-oxide electrodes optimized at the percolation thickness of AgOx for transparent silicon thin-film solar cells. Sol. Energy Mater. Sol. Cells 2019, 202, 110131. [CrossRef]

39. Wu, C.; Li, R.; Wang, Y.; Lu, S.; Lin, J.; Liu, Y.; Zhang, X. Strong metal-support interactions enable highly transparent Pt-Mo2C counter electrodes of bifacial dye-sensitized solar cells. Chem. Commun. 2020. [CrossRef]

40. Wu, X.; Zheng, S.; Bellido-Aguilar, D.A.; Silberschmidt, V.V.; Chen, Z. Transparent icephobic coatings using bio-based epoxy resin. Mater. Des. 2018, 140, 516-523. [CrossRef]

41. Park, S.-A.; Eom, Y.; Jeon, H.; Koo, J.M.; Lee, E.S.; Jegal, J.; Hwang, S.Y.; Oh, D.X.; Park, J. Preparation of synergistically reinforced transparent bio-polycarbonate nanocomposites with highly dispersed cellulose nanocrystals. Green Chem. 2019, 21, 5212-5221. [CrossRef]

42. Cárdenas-Martínez, J.; España-Sánchez, B.L.; Esparza, R.; Ávila-Niño, J.A. Flexible and transparent supercapacitors using electrospun PEDOT:PSS electrodes. Synth. Met. 2020, 267, 116436. [CrossRef]

43. Ishigami, A.; Watanabe, K.; Kurose, T.; Ito, H. Physical and morphological properties of tough and transparent PMMA-based blends modified with polyrotaxane. Polymers (Basel) 2020, 12, 1790. [CrossRef] [PubMed]

44. Trachtenberg, A.; Vinod, T.; Jelinek, R. Transparent, conductive polystyrene in three dimensional configurations. Polymer 2014, 55, 5095-5101. [CrossRef]

45. Kim, J.-H.; Mun, C.; Ma, J.; Park, S.-G.; Lee, S.; Kim, C.S. Simple fabrication of transparent, colorless, and self-disinfecting polyethylene terephthalate film via cold plasma treatment. Nanomaterials 2020, 10, 949. [CrossRef] 
46. Subba Rao, A.N.; Nagarajappa, G.B.; Nair, S.; Chathoth, A.M.; Pandey, K.K. Flexible transparent wood prepared from poplar veneer and polyvinyl alcohol. Compos. Sci. Technol. 2019, 182, 107719. [CrossRef]

47. Liu, Y.; Yang, H.; Ma, C.; Luo, S.; Xu, M.; Wu, Z.; Li, W.; Liu, S. Luminescent transparent wood based on lignin-derived carbon dots as a building material for dual-channel, real-time, and visual detection of formaldehyde gas. ACS Appl. Mater. Interfaces 2020, 12, 36628-36638. [CrossRef]

48. Zhang, L.; Wang, A.; Zhu, T.; Chen, Z.; Wu, Y.; Gao, Y. Transparent wood composites fabricated by impregnation of epoxy Resin and W-Doped VO2 nanoparticles for application in energy-saving windows. ACS Appl. Mater. Interfaces 2020, 12, 34777-34783. [CrossRef]

49. Chen, L.; Xu, Z.; Wang, F.; Duan, G.; Xu, W.; Zhang, G.; Yang, H.; Liu, J.; Jiang, S. A flame-retardant and transparent wood/polyimide composite with excellent mechanical strength. Compos. Commun. 2020, 20, 100355. [CrossRef]

50. Mi, R.; Chen, C.; Keplinger, T.; Pei, Y.; He, S.; Liu, D.; Li, J.; Dai, J.; Hitz, E.; Yang, B.; et al. Scalable aesthetic transparent wood for energy efficient buildings. Nat. Commun. 2020, 11, 3836. [CrossRef] [PubMed]

51. Liaw, D.-J.; Wang, K.-L.; Huang, Y.-C.; Lee, K.-R.; Lai, J.-Y.; Ha, C.-S. Advanced polyimide materials: Syntheses, physical properties and applications. Prog. Polym. Sci. 2012, 37, 907-974. [CrossRef]

52. Ni, H.-J.; Liu, J.-G.; Wang, Z.-H.; Yang, S.-Y. A review on colorless and optically transparent polyimide films: Chemistry, process and engineering applications. J. Ind. Eng. Chem. 2015, 28, 16-27. [CrossRef]

53. Kim, J.W.; Chang, J.-H. Syntheses of colorless and transparent polyimide membranes for microfiltration. Polymers 2020, 12, 1610. [CrossRef] [PubMed]

54. Tao, P.; Li, Y.; Rungta, A.; Viswanath, A.; Gao, J.; Benicewicz, B.C.; Siegel, R.W.; Schadler, L.S. TiO2 nanocomposites with high refractive index and transparency. J. Mater. Chem. 2011, 21, 18623-18629. [CrossRef]

55. Wu, M.; Wu, Y.; Liu, Z.; Liu, H. Optically transparent poly(methyl methacrylate) composite films reinforced with electrospun polyacrylonitrile nanofibers. J. Compos. Mater. 2012, 46, 2731-2738. [CrossRef]

56. Tang, C.; Liu, H. Cellulose nanofiber reinforced poly(vinyl alcohol) composite film with high visible light transmittance. Compos. Part A Appl. Sci. Manuf. 2008, 39, 1638-1643. [CrossRef]

57. Zhu, H.; Parvinian, S.; Preston, C.; Vaaland, O.; Ruan, Z.; Hu, L. Transparent nanopaper with tailored optical properties. Nanoscale 2013, 5, 3787-3792. [CrossRef] [PubMed]

58. Li, B.; Pan, S.; Yuan, H.; Zhang, Y. Optical and mechanical anisotropies of aligned electrospun nanofibers reinforced transparent PMMA nanocomposites. Compos. Part A Appl. Sci. Manuf. 2016, 90, 380-389. [CrossRef]

59. Koo, S.H.; Lee, S.G.; Bong, H.; Kwark, Y.-J.; Cho, K.; Lim, H.S.; Cho, J.H. Robust multifunctional superhydrophobic organicinorganic hybrid macroporous coatings and films. Polymer 2014, 55, 2661-2666. [CrossRef]

60. Wang, X.-F.; Huang, Z.-M.; Chen, L.-S. Comparison study on transparent composites with different patterns of nanofiber reinforcement. Fibers Polym. 2011, 12, 359-365. [CrossRef]

61. Cai, J.; Chen, J.; Zhang, Q.; Lei, M.; He, J.; Xiao, A.; Ma, C.; Li, S.; Xiong, H. Well-aligned cellulose nanofiber-reinforced polyvinyl alcohol composite film: Mechanical and optical properties. Carbohydr. Polym. 2016, 140, 238-245. [CrossRef]

62. Unal, S.; Arslan, S.; Karademir Yilmaz, B.; Kazan, D.; Oktar, F.N.; Gunduz, O. Glioblastoma cell adhesion properties through bacterial cellulose nanocrystals in polycaprolactone/gelatin electrospun nanofibers. Carbohydr. Polym. 2020, $233,115820$. [CrossRef]

63. Pan, N.; Qin, J.; Feng, P.; Song, B. Window screen inspired fibrous materials with anisotropic thickness gradients for improving light transmittance. Nanoscale 2019, 11, 13521-13531. [CrossRef] [PubMed]

64. Jiang, S.; Greiner, A.; Agarwal, S. Short nylon-6 nanofiber reinforced transparent and high modulus thermoplastic polymeric composites. Compos. Sci. Technol. 2013, 87, 164-169. [CrossRef]

65. Matabola, K.P.; de Vries, A.R.; Luyt, A.S.; Kumar, R. Studies on single polymer composites of poly(methyl methacrylate) reinforced with electrospun nanofibers with a focus on their dynamic mechanical properties. Express Polym. Lett. 2011, 5, 635-642. [CrossRef]

66. Zhou, H.; Zhang, M.; Pan, W. Preparation of free-standing flexible conductive silver submicron fiber network by direct electrospinning. Mater. Lett. 2021, 286, 129273. [CrossRef]

67. Avc1, M.Z.; Saraç, A.S. Transparent poly(methyl methacrylate-co-butyl acrylate) nanofibers. J. Appl. Polym. Sci. 2013, 130, 4264-4272. [CrossRef]

68. Reddy, C.S.; Zak, A.; Zussman, E. WS2 nanotubes embedded in PMMA nanofibers as energy absorptive material. J. Mater. Chem. 2011, 21, 16086-16093. [CrossRef]

69. Dulgerbaki, C.; Komur, A.I.; Maslakci, N.N.; Kuralay, F.; Oksuz, A.U. Synergistic tungsten oxide/organic framework hybrid nanofibers for electrochromic device application. Opt. Mater. 2017, 70, 171-179. [CrossRef]

70. Chen, R.; Zhang, H.; Wang, M.; Zhang, X.; Gan, Z. Thermoplastic polyurethane nanofiber membrane based air filters for efficient removal of ultrafine particulate matter PM0. ACS Appl. Nano Mater. 2021, 4, 182-189. [CrossRef]

71. Ruan, D.; Qin, L.; Chen, R.; Xu, G.; Su, Z.; Cheng, J.; Xie, S.; Cheng, F.; Ko, F.K. Transparent PAN:TiO 2 and PAN-co-PMA:TiO 2 nanofiber composite membranes with high efficiency in particulate matter pollutants filtration. Nanoscale Res. Lett. 2020, 15, 7. [CrossRef]

72. Orash Mahmoud Salehi, A.; Nourbakhsh, M.S.; Rafienia, M.; Baradaran-Rafii, A.; Heidari Keshel, S. Corneal stromal regeneration by hybrid oriented poly (E-caprolactone)/lyophilized silk fibroin electrospun scaffold. Int. J. Biol. Macromol. 2020, 161, 377-388. [CrossRef] 
73. Behler, K.D.; Stravato, A.; Mochalin, V.; Korneva, G.; Yushin, G.; Gogotsi, Y. Nanodiamond-polymer composite fibers and coatings. ACS Nano 2009, 3, 363-369. [CrossRef]

74. Lee, C.; Pant, B.; Alam, A.-M.; An, T.; Chung, H.-J.; Hong, S.-T.; Park, S.-J.; Park, M.; Kim, H.Y. Biocompatible and photoluminescent keratin/poly(vinyl alcohol)/carbon quantum dot nanofiber: A novel multipurpose electrospun mat. Macromol. Res. 2016, 24, 924-930. [CrossRef]

75. Arrieta, M.P.; López de Dicastillo, C.; Garrido, L.; Roa, K.; Galotto, M. Electrospun PVA fibers loaded with antioxidant fillers extracted from Durvillaea antarctica algae and their effect on plasticized PLA bionanocomposites. Eur. Polym. J. 2018, 103, 145-157. [CrossRef]

76. Najarzadekan, H.; Sereshti, H. Transparent polycaprolactam electrospun nanofibers doped with 1,10-phenanthroline optical sensor for colorimetric determination of iron (II) and vitamin C. Fibers Polym. 2018, 19, 2149-2156. [CrossRef]

77. Stachewicz, U.; Modaresifar, F.; Bailey, R.J.; Peijs, T.; Barber, A.H. Manufacture of void-free electrospun polymer nanofiber composites with optimized mechanical properties. ACS Appl. Mater. Interfaces 2012, 4, 2577-2582. [CrossRef] [PubMed]

78. Liao, H.Q.; Wu, Y.Q.; Wu, M.Y.; Zhan, X.R.; Liu, H.Q. Aligned electrospun cellulose fibers reinforced epoxy resin composite films with high visible light transmittance. Cellulose 2012, 19, 111-119. [CrossRef]

79. Ding, Z.; Zhu, Y.; Branford-White, C.; Sun, K.; Um-I-Zahra, S.; Quan, J.; Nie, H.; Zhu, L. Self-assembled transparent conductive composite films of carboxylated multi-walled carbon nanotubes/poly(vinyl alcohol) electrospun nanofiber mats. Mater. Lett. 2014, 128, 310-313. [CrossRef]

80. Ma, K.; Qiu, Y.P.; Fu, Y.Q.; Ni, Q.-Q. Electrospun sandwich configuration nanofibers as transparent membranes for skin care drug delivery systems. J. Mater. Sci. 2018, 53, 10617-10626. [CrossRef]

81. Kurokawa, N.; Hotta, A. Thermomechanical properties of highly transparent self-reinforced polylactide composites with electrospun stereocomplex polylactide nanofibers. Polymer 2018, 153, 214-222. [CrossRef]

82. Lu, Y.; Xiao, X.D.; Zhan, Y.J.; Cao, Z.Y.; Cheng, H.L.; Huan, C.M.; Qi, S.; Xu, G. Functional transparent nanocomposite film with thermochromic and hydrophobic properties fabricated by electrospinning and hot-pressing approach. Ceram. Int. 2018, 44, 1013-1018. [CrossRef]

83. Li, B.Y.; Yuan, H.H.; Zhang, Y.Z. Transparent PMMA-based nanocomposite using electrospun graphene-incorporated PA-6 nanofibers as the reinforcement. Compos. Sci. Technol. 2013, 89, 134-141. [CrossRef]

84. An, T.; Pant, B.; Kim, S.Y.; Park, M.; Park, S.J.; Kim, H.Y. Mechanical and optical properties of electrospun nylon-6,6 nanofiber reinforced cyclic butylene terephthalate composites. J. Ind. Eng. Chem. 2017, 55, 35-39. [CrossRef]

85. Jiang, S.; Hou, H.; Greiner, A.; Agarwal, S. Tough and transparent nylon-6 electrospun nanofiber reinforced melamineformaldehyde composites. ACS Appl. Mater. Interfaces 2012, 4, 2597-2603. [CrossRef] [PubMed]

86. Shin, J.-W.; Cho, W.-J. Carrier concentration and threshold voltage variability of amorphous oxide semiconductors using vacuum rapid thermal annealing. J. Nanosci. Nanotechnol. 2020, 20, 4276-4281. [CrossRef]

87. Yoon, S.; Kim, H.; Shin, E.-S.; Huh, J.N.; Noh, Y.-Y.; Park, B.; Hwang, I. Toward high conductivity of electrospun indium tin oxide nanofibers with fiber morphology dependent surface coverage: Postannealing and polymer ratio effects. ACS Appl. Mater. Interfaces 2017, 9, 34305-34313. [CrossRef]

88. Ning, Y.; Zhang, Z.; Teng, F.; Fang, X. Novel transparent and self-powered UV photodetector based on crossed ZnO nanofiber array homojunction. Small 2018, 14, e1703754. [CrossRef] [PubMed]

89. Lamastra, F.; Nanni, F.; Menchini, F.; Nunziante, P.; Grilli, M.L. Transparent nanostructured electrodes: Electrospun NiO nanofibers/NiO films. Thin Solid Films 2016, 601, 54-58. [CrossRef]

90. Cherpinski, A.; Torres-Giner, S.; Cabedo, L.; Lagaron, J.M. Post-processing optimization of electrospun submicron poly(3hydroxybutyrate) fibers to obtain continuous films of interest in food packaging applications. Food Addit. Contam. Part A Chem. Anal. Control Expo. Risk. Assess. 2017, 34, 1817-1830. [CrossRef] [PubMed]

91. Wagner, A.M.; Spencer, D.S.; Peppas, N.A. Advanced architectures in the design of responsive polymers for cancer nanomedicine. J. Appl. Polym. Sci. 2018, 135, 46154. [CrossRef] [PubMed]

92. Ji, S.; Hyun, B.G.; Kim, K.; Lee, S.Y.; Kim, S.-H.; Kim, J.-Y.; Song, M.H.; Park, J.-U. Photo-patternable and transparent films using cellulose nanofibers for stretchable origami electronics. NPG Asia Mater. 2016, 8, e299. [CrossRef]

93. Shin, D.-Y.; Park, E.-H.; Kim, K.-H. Moiré-fringeless transparent conductive films with a random serpentine network of mediumfield electrospun, chemically annealed silver microfibres. Sci. Rep. 2019, 9, 11226. [CrossRef]

94. Qiu, J.; Yu, T.; Zhang, W.; Zhao, Z.; Zhang, Y.; Ye, G.; Zhao, Y.; Du, X.; Liu, X.; Yang, L.; et al. A bioinspired, durable, and nondisposable transparent graphene skin electrode for electrophysiological signal detection. ACS Mater. Lett. 2020, 2, $999-1007$. [CrossRef]

95. Hong, E.-K.; Cho, W.-J. Microwave calcination of electrospun ITO nanofibers and improvement of transparent electrode characteristics through vacuum rapid thermal annealing. Mater. Res. Express 2020, 7, 075013. [CrossRef]

96. Mele, E.; Heredia-Guerrero, J.A.; Bayer, I.S.; Ciofani, G.; Genchi, G.G.; Ceseracciu, L.; Davis, A.; Papadopoulou, E.L.; Barthel, M.J.; Marini, L.; et al. Zwitterionic nanofibers of super-glue for transparent and biocompatible multi-purpose coatings. Sci. Rep. 2015, 5, 14019. [CrossRef] [PubMed]

97. Hsieh, T.-H.; Wang, Y.-Z.; Tseng, P.-H.; Ho, K.-S.; Tsai, Y.-J. Electrospun highly transparent, conducting Ag@polyacrylonitrile nanofibers prepared by post thermal treatment in the presence of tetraanilines. Polym. Degrad. Stab. 2017, 144, 146-154. [CrossRef] 
98. Zhao, Y.; Wang, X.; Zhang, Q.; Li, N. Preparation of transparent polyacrylonitrile reinforced polyurethane film and application as temperature monitor. Polym. Eng. Sci. 2018, 58, 1905-1910. [CrossRef]

99. Cho, Y.-Y.; Kuo, C. Optical and electrical characterization of electrospun Al-doped zinc oxide nanofibers as transparent electrodes. J. Mater. Chem. C 2016, 4, 7649-7657. [CrossRef]

100. Preda, N.; Evanghelidis, A.; Enculescu, M.; Florica, C.; Enculescu, I. Zinc oxide electroless deposition on electrospun PMMA fiber mats. Mater. Lett. 2015, 138, 238-242. [CrossRef]

101. Tao, D.; Wei, Q.; Cai, Y.; Xu, Q.; Sun, L. Functionalization of polyamide 6 nanofibers by electroless deposition of copper. J. Coat. Technol. Res. 2008, 5, 399-403. [CrossRef]

102. Pinto, N.; Carrión, P.; Quiñones, J. Electroless deposition of nickel on electrospun fibers of 2-acrylamido-2-methyl-1propanesulfonic acid doped polyaniline. Mater. Sci. Eng. A 2004, 366, 1-5. [CrossRef]

103. Hsu, P.-C.; Kong, D.; Wang, S.; Wang, H.; Welch, A.J.; Wu, H.; Cui, Y. Electrolessly deposited electrospun metal nanowire transparent electrodes. J. Am. Chem. Soc. 2014, 136, 10593-10596. [CrossRef]

104. Testa, A.; Bernasconi, R.; Yoshikawa, R.; Takenaka, I.; Magagnin, L.; Shiratori, S. Transparent flexible electrodes based on junctionless copper nanowire network via selective electroless metallization of electrospun nanofibers. J. Electrochem. Soc. 2017, 164, D764-D770. [CrossRef]

105. Matei, E.; Busuioc, C.; Evanghelidis, A.; Zgura, I.; Enculescu, M.; Beregoi, M.; Enculescu, I. Hierarchical functionalization of electrospun fibers by electrodeposition of zinc oxide nanostructures. Appl. Surf. Sci. 2018, 458, 555-563. [CrossRef]

106. Kim, G.H.; Woo, H.; Kim, S.; An, T.; Lim, G. Highly-robust, solution-processed flexible transparent electrodes with a junction-free electrospun nanofiber network. RSC Adv. 2020, 10, 9940-9948. [CrossRef]

107. Vinod, T.; Yin, X.; Jopp, J.; Jelinek, R. Directed self-assembly of graphene oxide on an electrospun polymer fiber template. Carbon 2015, 95, 888-894. [CrossRef]

108. Singh, S.B.; Hu, Y.; Kshetri, T.; Kim, N.H.; Lee, J.H. An embedded-PVA@Ag nanofiber network for ultra-smooth, high performance transparent conducting electrodes. J. Mater. Chem. C 2017, 5, 4198-4205. [CrossRef]

109. Jo, H.S.; An, S.; Lee, J.-G.; Park, H.G.; Al-Deyab, S.S.; Yarin, A.L.; Yoon, S.S. Highly flexible, stretchable, patternable, transparent copper fiber heater on a complex 3D surface. NPG Asia Mater. 2017, 9, e347. [CrossRef]

110. Jiang, D.-H.; Tsai, P.-C.; Kuo, C.-C.; Jhuang, F.-C.; Guo, H.-C.; Chen, S.-P.; Liao, Y.-C.; Satoh, T.; Tung, S. Facile preparation of $\mathrm{Cu} / \mathrm{Ag}$ core/shell electrospun nanofibers as highly stable and flexible transparent conductive electrodes for optoelectronic devices. ACS Appl. Mater. Interfaces 2019, 11, 10118-10127. [CrossRef]

111. Daneshvar, F.; Tagliaferri, S.; Chen, H.; Zhang, T.; Liu, C.; Sue, H.-J. Ultra-long electrospun copper-carbon nanotube composite fibers for transparent conductive electrodes with high operational stability. ACS Appl. Electron. Mater. 2020, 2, $2692-2698$. [CrossRef]

112. Beregoi, M.; Preda, N.; Costas, A.; Enculescu, M.; Negrea, R.F.; Iovu, H.; Enculescu, I. Synthesis of core-double shell nylon$\mathrm{ZnO} /$ polypyrrole electrospun nanofibers. Nanomaterials 2020, 10, 2241. [CrossRef]

113. An, S.; Kim, Y.I.; Jo, H.S.; Kim, M.-W.; Swihart, M.T.; Yarin, A.L.; Yoon, S.S. Oxidation-resistant metallized nanofibers as transparent conducting films and heaters. Acta Mater. 2018, 143, 174-180. [CrossRef]

114. Luo, H.; Hu, J.; Dou, Y.; Yang, Y.; Hou, J. Rapid visual alcohol dipstick based on transparent detection of hierarchical structured PLA/PVDF electrospun nanofibrous membrane. Compos. Commun. 2020, 22, 100516. [CrossRef]

115. Liu, C.; Hsu, P.-C.; Lee, H.-W.; Ye, M.; Zheng, G.; Liu, N.; Li, W.; Cui, Y. Transparent air filter for high-efficiency PM2.5 capture. Nat. Commun. 2015, 6, 6205. [CrossRef]

116. Liu, H.; Huang, J.; Mao, J.; Chen, Z.; Chen, G.; Lai, Y. Transparent antibacterial nanofiber air filters with highly efficient moisture resistance for sustainable particulate matter capture. iScience 2019, 19, 214-223. [CrossRef] [PubMed]

117. Liang, W.; Xu, Y.; Li, X.; Wang, X.-X.; Zhang, H.-D.; Yu, M.; Ramakrishna, S.; Long, Y.-Z. Transparent polyurethane nanofiber air filter for high-efficiency PM2.5 capture. Nanoscale Res. Lett. 2019, 14, 361. [CrossRef]

118. Mikheev, A.Y.; Kanev, I.L.; Morozova, T.Y.; Morozov, V.N. Water-soluble filters from ultra-thin polyvinylpirrolidone nanofibers. J. Membr. Sci. 2013, 448, 151-159. [CrossRef]

119. Parkin, I.P.; Palgrave, R.G. Self-cleaning coatings. J. Mater. Chem. 2005, 15, 1689-1695. [CrossRef]

120. Erbil, H.Y.; Demirel, A.L.; Avc1, Y.; Mert, O. Transformation of a Simple Plastic into a Superhydrophobic Surface. Science 2003, 299, 1377-1380. [CrossRef]

121. Matthews, J.A.; Wnek, G.E.; Simpson, D.G.; Bowlin, G.L. Electrospinning of collagen nanofibers. Biomacromolecules 2002, 3, 232-238. [CrossRef]

122. Arica, T.A.; Guzelgulgen, M.; Yildiz, A.A.; Demir, M.M. Electrospun GelMA fibers and p(HEMA) matrix composite for corneal tissue engineering. Mater. Sci. Eng. C 2021, 120, 111720. [CrossRef] [PubMed]

123. Tonsomboon, K.; Oyen, M.L. Composite electrospun gelatin fiber-alginate gel scaffolds for mechanically robust tissue engineered cornea. J. Mech. Behav. Biomed. Mater. 2013, 21, 185-194. [CrossRef]

124. Doshi, J.; Reneker, D.H. Electrospinning process and applications of electrospun fibers. J. Electrost. 1995, 35, 151-160. [CrossRef]

125. Li, M.; Guo, Y.; Wei, Y.; MacDiarmid, A.G.; Lelkes, P.I. Electrospinning polyaniline-contained gelatin nanofibers for tissue engineering applications. Biomaterials 2006, 27, 2705-2715. [CrossRef]

126. Jin, H.-J.; Fridrikh, S.V.; Rutledge, G.C.; Kaplan, D.L. Electrospinning Bombyx mori silk with poly(ethylene oxide). Biomacromolecules 2002, 3, 1233-1239. [CrossRef] [PubMed] 
127. Costa, L.M.M.; De Olyveira, G.M.; Basmaji, P.; Filho, L.X. Bacterial cellulose towards functional medical materials. J. Biomater. Tissue Eng. 2012, 2, 185-196. [CrossRef]

128. Svensson, A.; Nicklasson, E.; Harrah, T.; Panilaitis, B.; Kaplan, D.; Brittberg, M.; Gatenholm, P. Bacterial cellulose as a potential scaffold for tissue engineering of cartilage. Biomaterials 2005, 26, 419-431. [CrossRef]

129. Kim, D.-H.; Han, K.; Gupta, K.; Kwon, K.W.; Suh, K.-Y.; Levchenko, A. Mechanosensitivity of fibroblast cell shape and movement to anisotropic substratum topography gradients. Biomaterials 2009, 30, 5433-5444. [CrossRef]

130. Bäckdahl, H.; Helenius, G.; Bodin, A.; Nannmark, U.; Johansson, B.R.; Risberg, B.; Gatenholm, P. Mechanical properties of bacterial cellulose and interactions with smooth muscle cells. Biomaterials 2006, 27, 2141-2149. [CrossRef]

131. Kim, J.; Kim, S.W.; Park, S.; Lim, K.T.; Seonwoo, H.; Kim, Y.; Hong, B.H.; Choung, Y.-H.; Chung, J.H. Bacterial cellulose nanofibrillar patch as a wound healing platform of tympanic membrane perforation. Adv. Health Mater. 2013, 2, $1525-1531$. [CrossRef] [PubMed]

132. Grill, A. Diamond-like carbon coatings as biocompatible materials-An overview. Diam. Relat. Mater. 2003, 12, 166-170. [CrossRef]

133. Duy, L.T.; Trung, T.Q.; Hanif, A.; Siddiqui, S.; Roh, E.; Lee, W.; Lee, N.-E. A stretchable and highly sensitive chemical sensor using multilayered network of polyurethane nanofibres with self-assembled reduced graphene oxide. 2D Mater. 2017, 4, 025062. [CrossRef]

134. Fuh, Y.-K.; Li, S.-C.; Chen, C.-Y.; Tsai, C.-Y. A fully packaged self-powered sensor based on near-field electrospun arrays of poly(vinylidene fluoride) nano/micro fibers. Express Polym. Lett. 2018, 12, 136-145. [CrossRef]

135. Ünsal, Ö.F.; Altın, Y.; Çelik Bedeloglu, A. Poly(vinylidene fluoride) nanofiber-based piezoelectric nanogenerators using reduced graphene oxide/polyaniline. J. Appl. Polym. Sci. 2019, 137. [CrossRef]

136. Kim, S.-R.; Yoo, J.-H.; Park, J.-W. Using Electrospun AgNW/P(VDF-TrFE) composite nanofibers to create transparent and wearable single-electrode triboelectric nanogenerators for self-powered touch panels. ACS Appl. Mater. Interfaces 2019, 11, 15088-15096. [CrossRef] [PubMed]

137. Zhou, H.; Song, Y. Fabrication of Silver Mesh/Grid and Its Applications in Electronics. ACS Appl. Mater. Interfaces 2021, 13, 3493-3511. [CrossRef]

138. Lv, R.; Li, S.; Jin, T.; Na, B.; Zhou, H.; Liu, H. Hybrid core-shell nanofibers as moisture sensors for human breath monitoring. Compos. Sci. Technol. 2018, 162, 58-63. [CrossRef]

139. Wang, J.; Lou, Y.; Wang, B.; Sun, Q.; Zhou, M.; Li, X. Highly sensitive, breathable, and flexible pressure sensor based on electrospun membrane with assistance of AgNW/TPU as composite dielectric layer. Sensors 2020, 20, 2459. [CrossRef] [PubMed]

140. Li, P.; Zhang, W.; Ma, J.G.; Wang, X.; Xu, H.Y.; Cong, L.J.; Liu, Y.C. Solution-grown serpentine silver nanofiber meshes for stretchable transparent conductors. Adv. Electron. Mater. 2018, 4, 1800346. [CrossRef]

141. Choi, S.; Eom, Y.; Kim, S.; Jeong, D.; Han, J.; Koo, J.M.; Hwang, S.Y.; Park, J.; Oh, D.X. A Self-healing nanofiber-based selfresponsive time-temperature indicator for securing a cold-supply chain. Adv. Mater. 2020, 32, e1907064. [CrossRef] [PubMed]

142. Yang, W.; Li, N.-W.; Zhao, S.; Yuan, Z.; Wang, J.; Du, X.; Wang, B.; Cao, R.; Li, X.; Xu, W.; et al. A breathable and screen-printed pressure sensor based on nanofiber membranes for electronic skins. Adv. Mater. Technol. 2018, 3. [CrossRef]

143. Miyamoto, A.; Lee, S.; Cooray, N.F.; Lee, S.; Mori, M.; Matsuhisa, N.; Jin, H.; Yoda, L.; Yokota, T.; Itoh, A.; et al. Inflammation-free, gas-permeable, lightweight, stretchable on-skin electronics with nanomeshes. Nat. Nanotechnol. 2017, 12, 907-913. [CrossRef]

144. Azuma, K.; Sakajiri, K.; Okabe, T.; Matsumoto, H.; Kang, S.; Watanabe, J.; Tokita, M. Zero percolation threshold in electric conductivity of aluminum nanowire network fabricated by chemical etching using an electrospun nanofiber mask. Jpn. J. Appl. Phys. 2017, 56, 095002. [CrossRef]

145. Chen, H.-T.; Lin, H.-L.; Kuo, C.; Chen, I.-G. UV-induced synthesis of silver nanofiber networks as transparent electrodes. J. Mater. Chem. C 2016, 4, 7675-7682. [CrossRef]

146. Wu, H.; Hu, L.; Rowell, M.W.; Kong, D.; Cha, J.J.; McDonough, J.R.; Zhu, J.; Yang, Y.; McGehee, M.D.; Cui, Y. Electrospun metal nanofiber webs as high-performance transparent electrode. Nano Lett. 2010, 10, 4242-4248. [CrossRef] [PubMed]

147. Duzyer, S.; Cunayev, S. Effect of deposition time on the optoelectrical properties of electrospun Pan/Agno3 nanofibers. Tekstil Ve Konfeksiyon 2019. [CrossRef]

148. Jung, H.; Chae, S.Y.; Kim, H.; Min, B.K.; Hwang, Y.J. Electrospun Mo-doped BiVO4 photoanode on a transparent conductive substrate for solar water oxidation. Catal. Commun. 2016, 75, 18-22. [CrossRef]

149. Li, P.; Ma, J.G.; Xu, H.Y.; Xue, X.D.; Liu, Y.C. Highly stable copper wire/alumina/polyimide composite films for stretchable and transparent heaters. J. Mater. Chem. C 2016, 4, 3581-3591. [CrossRef]

150. Devarayan, K.; Lei, D.; Kim, H.-Y.; Kim, B.-S. Flexible transparent electrode based on PANi nanowire/nylon nanofiber reinforced cellulose acetate thin film as supercapacitor. Chem. Eng. J. 2015, 273, 603-609. [CrossRef]

151. Wang, Q.X.; Hu, X.T.; Yang, X.; Liu, G.L.; Meng, X.C.; Xie, Y.P.; Xiao, Y.B.; Liu, J.L.; Tan, L.C.; Chen, Y.W. Large-scale ultra-adhesive and mechanically flexible silver grids transparent electrodes by solution process. Org. Electron. 2018, 61, 296-303. [CrossRef]

152. He, T.; Xie, A.; Reneker, D.H.; Zhu, Y. A Tough and high-performance transparent electrode from a scalable and transfer-free method. ACS Nano 2014, 8, 4782-4789. [CrossRef]

153. Kim, S.-W.; An, B.W.; Cho, E.; Hyun, B.G.; Moon, Y.-J.; Kim, S.-K.; Park, J. A full-visible-spectrum invisibility cloak for mesoscopic metal wires. Nano Lett. 2018, 18, 3865-3872. [CrossRef] [PubMed] 
154. He, H.; Li, X.; Wang, J.; Qiu, T.; Fang, Y.; Song, Q.; Luo, B.; Zhang, X.; Zhi, L. Reduced graphene oxide nanoribbon networks: A novel approach towards scalable fabrication of transparent conductive films. Small 2013, 9, 820-824. [CrossRef]

155. Huang, Y.-L.; Baji, A.; Tien, H.-W.; Yang, Y.-K.; Yang, S.-Y.; Wu, S.-Y.; Ma, C.-C.M.; Liu, H.-Y.; Mai, Y.-W.; Wang, N.-H. Self-assembly of silver-graphene hybrid on electrospun polyurethane nanofibers as flexible transparent conductive thin films. Carbon 2012, 50, 3473-3481. [CrossRef]

156. Tian, W.; Zhai, T.; Zhang, C.; Li, S.-L.; Wang, X.; Liu, F.; Liu, D.; Cai, X.; Tsukagoshi, K.; Golberg, D.; et al. Low-cost fully transparent ultraviolet photodetectors based on electrospun $\mathrm{ZnO}-\mathrm{SnO} 2$ heterojunction nanofibers. Adv. Mater. 2013, 25, 4625-4630. [CrossRef]

157. Nasreen, S.A.; Sundarrajan, S.; Nizar, S.A.; Balamurugan, R.; Ramakrishna, S. Advancement in electrospun nanofibrous membranes modification and their application in water treatment. Membranes 2013, 3, 266-284. [CrossRef] [PubMed]

158. Zhang, M.; Ma, W.; Cui, J.; Wu, S.; Han, J.; Zou, Y.; Huang, C. Hydrothermal synthesized UV-resistance and transparent coating composited superoloephilic electrospun membrane for high efficiency oily wastewater treatment. J. Hazard. Mater. 2020, 383, 121152. [CrossRef]

159. Ma, W.; Ding, Y.; Zhang, M.; Gao, S.; Li, Y.; Huang, C.; Fu, G. Nature-inspired chemistry toward hierarchical superhydrophobic, antibacterial and biocompatible nanofibrous membranes for effective UV-shielding, self-cleaning and oil-water separation. J. Hazard. Mater. 2020, 384, 121476. [CrossRef]

160. Torres-Giner, S.; Martinez-Abad, A.; Lagaron, J.M. Zein-based ultrathin fibers containing ceramic nanofillers obtained by electrospinning. II. Mechanical properties, gas barrier, and sustained release capacity of biocide thymol in multilayer polylactide films. J. Appl. Polym. Sci. 2014, 131, 40768. [CrossRef]

161. Melendez-Rodriguez, B.; Castro-Mayorga, J.L.; Reis, M.A.M.; Sammon, C.; Cabedo, L.; Torres-Giner, S.; Lagaron, J.M. Preparation and characterization of electrospun food biopackaging films of poly(3-hydroxybutyrate-co-3-hydroxyvalerate) derived from fruit pulp biowaste. Front. Sustain. Food Syst. 2018, 2. [CrossRef]

162. Figueroa-Lopez, K.; Enescu, D.; Torres-Giner, S.; Cabedo, L.; Cerqueira, M.; Pastrana, L.; Fuciños, P.; Lagaron, J. Development of electrospun active films of poly(3-hydroxybutyrate-co-3-hydroxyvalerate) by the incorporation of cyclodextrin inclusion complexes containing oregano essential oil. Food Hydrocoll. 2020, 108, 106013. [CrossRef]

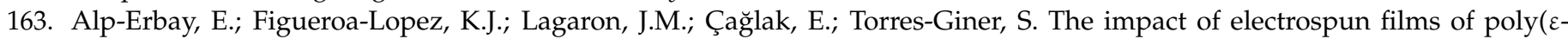
caprolactone) filled with nanostructured zeolite and silica microparticles on in vitro histamine formation by Staphylococcus aureus and Salmonella Paratyphi A. Food Packag. Shelf Life 2019, 22. [CrossRef]

164. Wang, Y.; Xue, J.; Wang, Q.; Chen, Q.; Ding, J. Verification of icephobic/anti-icing properties of a superhydrophobic surface. ACS Appl. Mater. Interfaces 2013, 5, 3370-3381. [CrossRef] [PubMed]

165. Zhu, T.; Cheng, Y.; Huang, J.; Xiong, J.; Ge, M.; Mao, J.; Liu, Z.; Dong, X.; Chen, Z.; Lai, Y. A transparent superhydrophobic coating with mechanochemical robustness for anti-icing, photocatalysis and self-cleaning. Chem. Eng. J. 2020, 399, 125746. [CrossRef]

166. $\mathrm{Wu}, \mathrm{X}$; Chen, Z. A mechanically robust transparent coating for anti-icing and self-cleaning applications. J. Mater. Chem. A 2018, 6 , 16043-16052. [CrossRef]

167. Tang, Y.; Zhang, Q.; Zhan, X.; Chen, F. Superhydrophobic and anti-icing properties at overcooled temperature of a fluorinated hybrid surface prepared via a sol-gel process. Soft Matter 2015, 11, 4540-4550. [CrossRef]

168. Tas, M.; Memon, H.; Xu, F.; Ahmed, I.; Hou, X. Electrospun nanofibre membrane based transparent slippery liquid-infused porous surfaces with icephobic properties. Colloids Surf. A Physicochem. Eng. Asp. 2020, 585, 124177. [CrossRef]

169. Tantawy, A.H.; Mohamed, I.M.; Zhu, J.-H.; Khalaf, M.M. An efficient synthesis of electrospun TiO ${ }_{2}$-nanofibers/Schiff base phenylalanine composite and its inhibition behavior for C-steel corrosion in acidic chloride environments. J. Taiwan Inst. Chem. Eng. 2020, 112, 306-321. [CrossRef]

170. Lee, M.W.; An, S.; Lee, C.; Liou, M.; Yarin, A.L.; Yoon, S.S. Self-healing transparent core-shell nanofiber coatings for anti-corrosive protection. J. Mater. Chem. A 2014, 2, 7045-7053. [CrossRef]

171. Ji, X.; Wang, W.; Li, W.; Zhao, X.; Liu, A.; Wang, X.; Zhang, X.; Fan, W.; Wang, Y.; Lu, Z.; et al. pH-responsible self-healing performance of coating with dual-action core-shell electrospun fibers. J. Taiwan Inst. Chem. Eng. 2019, 104, 227-239. [CrossRef]

172. Yang, J.; Liu, C.; Wang, B.; Ding, X. Feedback system control optimized electrospinning for fabrication of an excellent superhydrophobic surface. Nanomaterials 2017, 7, 319. [CrossRef] [PubMed]

173. Uzoma, P.C.; Liu, F.; Han, E.-H.; Uzoma, P.C. Multi-stimuli-triggered and self-repairable fluorocarbon organic coatings with urea-formaldehyde microcapsules filled with fluorosilane. J. Mater. Sci. Technol. 2020, 45, 70-83. [CrossRef]

174. An, S.; Liou, M.; Song, K.Y.; Jo, H.S.; Lee, M.W.; Al-Deyab, S.S.; Yarin, A.L.; Yoon, S.S. Highly flexible transparent self-healing composite based on electrospun core-shell nanofibers produced by coaxial electrospinning for anti-corrosion and electrical insulation. Nanoscale 2015, 7, 17778-17785. [CrossRef] [PubMed] 